\title{
Unresolved gustatory, olfactory and auditory adverse drug reactions to antibiotic drugs: a survey of spontaneous reporting to Eudravigilance
}

\section{Sara Ferraro, Irma Convertino, Luca Leonardi, Corrado Blandizzi \& Marco Tuccori}

To cite this article: Sara Ferraro, Irma Convertino, Luca Leonardi, Corrado Blandizzi \& Marco Tuccori (2019): Unresolved gustatory, olfactory and auditory adverse drug reactions to antibiotic drugs: a survey of spontaneous reporting to Eudravigilance, Expert Opinion on Drug Safety, DOI: 10.1080/14740338.2019.1676724

To link to this article: https://doi.org/10.1080/14740338.2019.1676724

Accepted author version posted online: 03

Oct 2019.

Submit your article to this journal ¿

Q View related articles ๘

View Crossmark data ¿ 
Publisher: Taylor \& Francis \& Informa UK Limited, trading as Taylor \& Francis Group

Journal: Expert Opinion on Drug Safety

DOI: $10.1080 / 14740338.2019 .1676724$

Unresolved gustatory, olfactory and auditory adverse drug reactions to antibiotic drugs: a survey of spontaneous reporting to Eudravigilance

${ }^{\S}$ Sara Ferraro ${ }^{1}$, Irma Convertino $^{1}$, Luca Leonardi ${ }^{1}$, Corrado Blandizzi $i^{1,2}$, Marco Tuccori ${ }^{1,2}$

${ }^{1}$ Unit of Pharmacology and Pharmacovigilance, Department of Clinical and Experimental Medicine, University of Pisa, Pisa, Italy

${ }^{2}$ Unit of Adverse Drug Reaction Monitoring, University Hospital of Pisa, Pisa, Italy

\section{$\S$ co-first authors}

\section{Corresponding author:}

Marco Tuccori,

Unit of Adverse Drug Reactions Monitoring, University Hospital of Pisa, Tuscan Regional Centre of Pharmacovigilance, Via Roma, 55, I-56126 Pisa, Italy

Tel.: +39-050-992071

Fax: $+39-050-2218758$

Email: m.tuccori@ao-pisa.toscana.it; marco.tuccori@gmail.com 


\begin{abstract}
Objectives: Sensory adverse drug reactions (ADRs) are generally expected to be transient in nature. However, spontaneous reports describe frequently these events as long-lasting or unresolved. In this study, the authors reviewed the Eudravigilance publicly accessible database to describe the volume and expectedness of potentially unresolved outcomes for gustatory, olfactory and auditory (GOA) suspected ADRs associated with antibiotics for systemic use.
\end{abstract}

Methods: "Overall" and "GOA" suspected ADRs were extracted from Eudravigilance, to estimate the distribution of their outcomes among different antibiotic groups. Then, the authors identified the drugs contributing to at least $15 \%$ of all suspected GOA ADRs observed for the antibiotic groups, and evaluated the expectedness.

Results: The frequency of persistent/permanent outcomes was higher for GOA suspected ADRs, as compared to the overall ones. Unresolved and undetermined outcomes for antibiotic-associated GOA ADRs in Eudravigilance might hide a large number of events with underestimated clinical consequences. Several persistent/permanent antibioticassociated GOA reactions could be classified as serious and unexpected.

Conclusion: Potential long-lasting or irreversible GOA reactions are often reported for all antibiotics drugs. Further studies are warranted to clarify whether this is an actual safety issue or simply it reflects a general difficulty in outcomes assessment for such reactions.

Key words: antibiotic, quinolone, sensory, gustatory, olfactory, auditory, unresolved, adverse drug reaction 


\section{Introduction}

Irreversible or persistent mild to moderate disabilities can be an important consequence of adverse drug reactions (ADRs) that strongly affect the quality of life. In 2017, the European Medicine Agency (EMA) started a review of the safety of fluoroquinolone and quinolone antibiotics, with a particular focus on the rare disabling, long-lasting and potentially permanent ADRs, mainly involving muscles, tendons, bones and the nervous system, including sensory ADRs. In November 2018, this review culminated with the recommendation by the Pharmacovigilance Risk Assessment Committee (PRAC) to suspend the marketing authorization of medicines containing quinolones (cinoxacin, flumequine, nalidixic acid and pipemidic acid) and to restrict the use of fluoroquinolones ${ }^{1}$.

Although some sensory alterations are labelled for several antibiotic drugs, these reactions are commonly known to be transient in nature. However, an analysis of taste and smell alterations, performed on the Italian spontaneous ADR reporting database and published in 2011, revealed that the reports for these reactions described frequently longlasting or unresolved outcomes, not only for fluoroquinolones, but also for other drug classes, including macrolide antibiotics ${ }^{2}$. Furthermore, irreversible auditory adverse reactions are labelled only for few antibiotic drugs, such as gentamycin and vancomycin, for which literature evidence about their ototoxicity is consistent ${ }^{3-5}$.

In this study, publicly accessible data collected in the Eudravigilance database were reviewed to describe the extent and expectedness of unresolved outcomes for gustatory, olfactory and auditory (GOA) suspected ADRs reported for antibiotics for systemic use. In particular, this study is aimed at identifying the antibiotics groups that could show a remarkable frequency of potentially persistent or permanent GOA reactions, taking into account the frequency of the same outcomes reported for overall suspected ADRs. Finally, we checked the expectedness of the observed GOA reactions, in order to evaluate whether other classes, besides quinolones, should deserve greater attention by health authorities, due to a possible underestimation of the clinical and social impact of such reactions.

\section{Methods}

\subsection{Data source}

In the present study, publicly accessible data of Eudravigilance database of spontaneously reported suspected ADRs (http://www.adrreports.eu/en/search subst.html), collected up to February 2019, were used. 


\subsection{Dictionary creation}

A dictionary of GOA ADRs, through the selection of Medical Dictionary for Regulatory Activities (MedDRA) Preferred Terms (PTs) referring to sensory adverse reactions related to gustatory, olfactory and auditory alterations, was created (Supplementary Table $1 \mathrm{a}-\mathrm{c}$ ). We excluded those conditions that can cause indirectly gustatory, olfactory and auditory disorders (e.g. traumatic events), and selected PTs that refer to drug-related impairments of impulses from mechanoreceptors (for audition sense) and chemoreceptors (for gustation and olfaction senses) to specific brain areas responsible for signal processing. The dictionary of the drugs of interest $(n=137)$ included every drug of the Anatomical Therapeutic Chemical (ATC) class J01 (antibacterial drugs for systemic use), for which at least a report of ADR was present in the Eudravigilance database (Supplementary Table 2).

\subsection{Data extraction}

The tool "Online access to suspected side-effect reports", available at www.adrreports.eu, was used to extract drug-event pairs of interest. For each antibiotic drug, the total number of "overall" ADRs as well as the total number and specific events for GOA suspected ADRs were extracted in accordance with PTs reported in the dictionary, as defined above. Each GOA drug-event pair was classified according to its outcome ("fatal", "not recovered/not resolved", "not specified", "recovered/resolved", "recovered/resolved with sequelae", "recovering/resolving", and "unknown"). Fatal outcomes were associated to a lack of detention of resolution of GOA reactions. The outcomes were then organized in three larger groups: defined outcomes ("recovered/resolved"), persistent or permanent outcomes ("not recovered/not resolved", "recovered/resolved with sequelae" and "recovering/resolving") and undetermined outcomes ("not specified", "unknown" and "fatal").

\subsection{Data analysis}

The extracted data were organized in accordance with third and fourth level of ATC classification and a descriptive analysis was performed. Firstly, we assessed the distribution of defined, persistent/permanent and undetermined outcomes of drug-event pairs (both overall and GOA reactions) associated with third-level ATC classes (pharmacological subgroups). In particular, GOA reactions were analyzed further, allocating them into the three subcategories: gustatory reactions, auditory reactions and olfactory reactions. Pharmacological subgroups that resulted with less than 50 GOA reactions after data extraction were excluded from the analysis, and the distribution of 
defined, persistent/permanent and undetermined outcomes, related to overall and GOA reactions were assessed. Then, the antibiotics drugs that contributed with more than 50 GOA reactions to at least $15 \%$ of total GOA reactions, extracted for their respective antibiotic groups, were identified. For these drugs, the expectedness of the extracted suspected GOA ADRs was finally evaluated through examination of their respective EMA Summary of Product Characteristics (SPC), or Italian Medicine Agency (AIFA) SPC (when the SPC was not available in the first source). When more than one SPC was available, the SPC of the originator medicinal product was used as reference source. The events included in the "undesirable effects" section (4.8) of SPCs were then compared to the adverse events' PTs found in Eudravigilance. In particular, each PT was defined as "listed" if it was exactly indexed in the SPC of the active compound of interest, while it was defined as "linked" if it was related, for clinical features and severity, to another PT already listed in the reference SPC. All the extracted PTs that were not identified either as listed or as linked were classified as "unlabelled". Any disagreement about this classification was resolved by discussion among the authors. A flowchart of data extraction and allocation is showed in figure 1.

\section{Results}

According to the selection criteria, 748,798 overall drug-event pairs were extracted. Supplementary Table 3 shows the number of drug-event pairs extracted from Eudravigilance for antibiotics belonging to the therapeutic group J01, according to thirdand fourth- levels of ATC classification. Drug-event pairs were classified as overall, GOA, gustatory, olfactory and auditory reactions. Table 1 displays the number of overall reactions for the most reported antibiotics groups, organized by frequency of GOA reactions with details of their outcomes. Seven groups have a percentage of GOA reactions $\geq 1 \%$. Aminoglycosides and macrolides show $5.6 \%$ and $4,2 \%$, respectively, followed by imidazole derivatives $(2.4 \%)$, lincosamides $(2 \%)$, tetracyclines $(1.6 \%)$, fluoroquinolones (1.5\%) and glycopeptide antibiotic drugs (1\%). As shown in Table 1, the frequency of persistent/permanent outcomes of GOA reactions (ranged between 36.3\% and $56.1 \%$ ) results greater than that of the overall ADRs (ranged between $15.4 \%$ and $33.9 \%$ ), except for quinolones, that show the lowest frequency of persistent/permanent overall reactions, but no persistent/permanent GOA reactions. Moreover, among the overall ADRs, persistent/permanent reactions are always less than the undetermined and the defined ones, except for nitrofuran derivatives. The other two outcome categories of 
overall reactions are distributed among the drug classes in a quite balanced way. On the contrary, persistent/permanent GOA reactions are often more than the undetermined and the defined ones, except for aminoglycoside (44.1\% of persistent/permanent versus $49 \%$ of undetermined reactions) and the second generation of cephalosporins, which show the lowest rate of persistent/permanent GOA reactions (36\% of persistent/permanent versus $49.2 \%$ of undetermined reactions).

At the top of the list, tetracyclines show a percentage of $56.1 \%$ of persistent/permanent outcomes, followed by the third generation of cephalosporins and nitrofuran derivatives $(50.8 \%$ and $50.6 \%$, respectively), imidazole derivatives $(50.4 \%)$, macrolides and fluoroquinolones (49.4\% and $49.3 \%$, respectively). The remaining classes gradually deviate from the $50 \%$ (range 39.4 - 46.9\%). Almost all the antibiotic groups show the same outcome's trend of GOA reactions: the highest frequency is usually associated with persistent/permanent outcome (36.3 - 56.1\%), followed by the undetermined one $(28.6-40.0 \%)$ and last by the defined outcome, $(6.7 \%-29.7 \%)$ with the lowest frequencies.

The distribution of persistent/permanent, undetermined and defined reactions among the three different category of GOA reactions (gustatory, olfactory and auditory) is shown in Supplementary Table 4. All the three categories of GOA reactions show the same trend of outcome distribution: persistent/permanent reactions are the most frequent ADRs, followed by the undetermined and the defined ones. When comparing gustatory reactions to the overall ones, we found that among the antibiotic classes, persistent/permanent gustatory reactions (12.0 - 53.9\%) are often more frequent than overall ones $(20.6-33.9 \%)$. Only sulfonamides and trimethoprim class and glycopeptide antibacterials show an opposite state. The distribution analysis of olfactory reactions, shows that all the antibiotic classes are associated with a greater frequency of persistent/permanent reactions (57.1 - 100.0\%) than overall ones (20.6 - 33.9\%). Any olfactory reaction was observed for glycopeptide antibiotics. Likewise, persistent/permanent auditory reactions are always more frequent $(33.3-53.7 \%)$ than the overall ones $(16.8-33.9 \%)$. In general, olfactory reactions show the highest rate of persistent/permanent outcomes, followed by auditory and gustatory reactions.

Among antibiotic classes, twenty drugs were selected for the expectedness assessment of GOA reactions, in agreement with inclusion criteria. The following antibiotics are representative of the antibiotic class they belong to: doxycycline and minocycline (tetracyclines); ceftriaxone (third generation of cephalosporins); nitrofurantoin 
(nitrofuran derivatives); metronidazole (imidazole derivatives); ciprofloxacin, levofloxacin and moxifloxacin (fluoroquinolones); clarithromycin and azithromycin (macrolides); vancomycin (glycopeptide antibacterials); amoxicillin/clavulanic acid (penicillins); amikacin, gentamycin and tobramycin (aminoglycosides); clindamycin (lincosamides); meropenem and imipenem/ciclastatin (carbapenems); linezolid (other antibacterials NEC); cefuroxime (third generation of cephalosporins). More detailed information is provided in Supplementary Table $5(a-n)$ that shows the amount of persistent/permanent, undetermined and defined GOA reactions associated with drugs belonging to the analyzed antibiotic groups.

Table 2 shows that all selected antibiotics have a greater frequency of persistent/permanent GOA reactions compared to the overall reactions. Eight antibiotics (i.e. azithromycin, tobramycin, doxycycline, metronidazole, moxifloxacin levofloxacin, minocycline and ceftriaxone) have a percentage of persistent/permanent reactions ranged between $50.4 \%$ and $60.9 \%$. Ten drugs (amikacin, gentamicin, clarithromycin, clindamycin, ciprofloxacin, vancomycin, imipenem/cilastatin, minocycline, meropenem and amoxicillin/clavulanic acid) show a frequency of persistent/permanent GOA reactions ranged between $40.1 \%$ and $48.1 \%$. Only linezolid and cefuroxime have a percentage of persistent/permanent GOA reaction under $40 \%$ (34.8\% and $34.4 \%$, respectively).

All the above-mentioned antibiotic drugs were evaluated for the expectedness, and the results of the analysis are listed in Table 3, which shows labelled ADRs reported in the originator's SPC as compared to the listed, linked and unlabelled suspected ADRs reported in Eudravigilance for each drug. Ciprofloxacin, clarithromycin, azithromycin are the only three drugs that do not show any unlabelled suspected GOA reaction, while all the other drugs have at least one unlabelled GOA reaction. In particular, unexpected gustatory, olfactory and auditory reactions were reported in Eudravigilance for 13, 14 and 13 antibiotic drugs, among the twenty included in this analysis.

\section{Discussion}

In the present analysis, the distribution of persistent/permanent, undetermined and defined outcomes recorded for the antibiotic groups showed a general trend toward a high proportion of persistent/permanent suspected ADRs in the GOA group as compared to the overall suspected ADRs. Indeed, persistent/permanent suspected ADRs represented less than one third of the overall reactions in every subgroup, and more than a half of the GOA 
reactions in most of the antibiotic classes. The proportion of undetermined GOA reactions resulted almost similar to that of undetermined overall ones across the different antibiotics.

The detailed data about gustatory, olfactory and auditory reactions, showed that among the classes under evaluation, olfactory reactions were generally the least frequently reported. This could depend on an actual low occurrence of olfactory adverse events or perhaps, patients or healthcare professionals might detect this kind of reactions more hardly. However, among the antibiotics groups, the percentage of persistent/permanent olfactory reactions was higher than that of persistent/permanent gustatory and auditory reactions. Carbapenems and tetracyclines were the antibiotics with the higher percentage of persistent/permanent olfactory reactions, followed by cephalosporins and nitrofuran derivatives. Of note, olfactory adverse reactions are not expected for these antibiotics. Data supporting drug-related events of olfactory impairment have been reported for tetracyclines ${ }^{6-8}$ but not for the other antibiotics. Furthermore, to the best of our knowledge, there is no evidence in medical literature supporting an association between these drug classes and permanent olfactory effects.

The distribution of outcomes related to gustatory reactions was quite homogeneous throughout the antibiotic classes. In particular, for most groups, persistent/permanent gustatory reactions were more than $40 \%$. Even for gustatory reactions, tetracyclines were the most frequently reported with persistent/permanent outcomes, although other classes (aminoglycosides, fluoroquinolones and imidazole derivatives) displayed quite similar frequencies. Notably, gustatory reactions are generally unexpected for tetracyclines and aminoglycosides, but labelled for fluoroquinolones ${ }^{2}$ and imidazole derivatives ${ }^{9}$. However, evidence about permanent gustatory reactions for these drugs are not documented in the literature, with a possible exception for fluoroquinolones ${ }^{1}$.

Persistent/permanent auditory reactions represented about half of the total auditory suspected reactions for almost all antibiotic classes, with exception carbapenems, lincosamides and second generation cephalosporins. Nitrofuran derivatives, third generation of cephalosporins, tetracyclines and imidazole derivatives showed the highest percentage of persistent/permanent outcomes. Auditory reactions are unlabelled for nitrofuran derivatives, cephalosporins and imidazole derivatives, while are expected for tetracyclines. Notably, drug-related auditory impairments attributed to metronidazole assumption are described in literature ${ }^{9,10}$, while some tetracyclines are well known to cause tinnitus, a specific hearing disorder ${ }^{11,12}$. 
These findings can be explained by an actual long-lasting or irreversible effect of antibiotics on nerves involved in gustatory, olfactory and auditory perception, or simply by a general difficulty in assessing the resolution of such adverse events. When biologic plausibility for these reactions is considered, auditory ADRs after aminoglycosides, such as deafness, are often described as a consequence of the degeneration of cochlear sensory hair cells. In particular, the damage to cochlear hair cells seems to occur due to oxidative stress, which begins in the basal area of the cochlea. However, differentiated hair cells can not be replaced by regeneration once they are lost, and thus a severe damage likely results in an irreversible hearing loss ${ }^{13,14}$. Contrary to the mechanisms of permanent auditory disorders caused by drugs, those related to gustatory or olfactory permanent impairments are less known, even though a similar pharmacodynamic detrimental effect on nerves could be hypothesized ${ }^{15}$. However, since these adverse events appear as a general issue of all antibiotics, it is unlikely that a unique common biological mechanism can explain these observations. Therefore, the general difficulty in assessing the ultimate outcome of GOA reactions remains the most likely hypothesis.

When expectedness is considered for the antibiotics most frequently associated with GOA reactions, we found that unexpected gustatory, olfactory and auditory reactions were reported in Eudravigilance for most of the listed drugs. In addition, only two drugs had information about the duration or severity of the adverse event in their SPC. Particularly, the gentamicin label reports the auditory ADR "irreversible deafness", and the vancomycin label reports the auditory ADR "permanent hearing loss". Of note, the duration of an ADR is a relevant information that might suggest a condition of irreversibility of the adverse event, and consequently a different attribution of seriousness. Accordingly to EMA guidelines on Good Pharmacovigilance Practices $(G V P)^{16}$, the definition of serious adverse drug reaction includes those adverse reactions resulting in persistent or significant disability or incapacity. GOA persistent and permanent ADRs can significantly affect quality of life ${ }^{17}$, and patients should be alerted about the potential irreversibility of adverse events caused by treatments. Considering that about $40-50 \%$ of GOA reactions reported in Eudravigilance for antibiotic drugs are potentially classifiable as persistent/permanent, we can hypothesize that several of these reactions meet the criteria for being classified as serious and unexpected. However, it is reasonable to suppose that these reactions have not been managed as such by both regulatory authorities and marketing authorization holders. It is important to note that the MedDRA dictionary reports the PT code "deafness permanent", while similar coding are not listed for olfactory and gustatory reactions. This 
could represent an important limitation for the identification of related signals in spontaneously reported ADR databases. Of note, a revision of the codification system would be warranted, since drug-related permanent gustatory and olfactory reactions are actually described in literature ${ }^{18-20}$.

Quinolones and fluoroquinolones have been analyzed separately. Indeed, we observed only one GOA reaction for quinolones among the few overall reactions (just 421) reported for this antibiotic class. On the contrary, fluoroquinolones had a greatest amount of GOA reactions (2628), with a percentage of $1.5 \%$ out of the large amount of overall reactions extracted for this antibiotic class. Notably, fluoroquinolones showed the same trend of most antibiotic classes. Among the GOA suspected ADRs, the persistent/permanent reactions covered the $49.1 \%$, making fluoroquinolones take the fourth position with macrolides, after imidazole derivatives $(50.4 \%)$, nitrofuran derivatives, third generation of cephalosporins (50.6 and $50.8 \%$, respectively) and tetracyclines (56.1\%). These results, confirm the possible association of permanent/persistent GOA reactions with fluoroquinolones exposure, but also highlight that other antibiotic classes could be further investigated.

The wide distribution of permanent/persistent GOA reactions compared to the overall ones among the analyzed antibiotic groups, and the extracted suspected GOA ADRs which were showed to be unexpected for some antibiotics, suggest that additional studies are needed to master these findings. Moreover, the extent of unresolved and undetermined outcomes for GOA reactions reported for antibacterial drugs in Eudravigilance might potentially hide a large number of events with underestimated clinical consequences. Indeed, apparently mild and transient reactions can strongly affect the quality of life when their outcomes become persistent. In general, when assessing the expectedness of a reported ADR, the persistence of signs and symptoms should be followed up carefully and improving the collaboration with patients in this process is essential, particularly with subjective ADRs, like GOA ones.

The study has some limitations. The most important one is the level of details available on publicly accessible Eudravigilance data. A consequence of this condition is the difficulty in the identification and exclusion of duplicates and in performing a causality assessment. Furthermore, the lack of information about the time to outcome after drug discontinuation would have been important to identify unresolved outcomes assessed after long time (potential permanent events). Therefore, we can not exclude of having misclassified some suspected ADRs as persistent/permanent simply because these were 
reported soon after their onset and there was no indication on the time of recovery. Moreover, we tried to include only PTs associated with gustatory, olfactory and auditory damages that are likely caused by direct neurological drug-related injury, however we cannot exclude that some codes could refer to traumatic damage, which could emerge only if the narrative of cases was available.

\section{Conclusion}

The study's findings showed that adverse reactions classified as persistent/permanent represent a wide proportion of total GOA reactions for all antibiotics drugs. The distribution of such outcomes is undoubtedly higher for GOA ADR reports as compared to the overall ones across the different antibiotic classes. This could mean that such reactions can be sometimes long-lasting or irreversible for several antibiotics. However, this finding might reflect also an intrinsic difficulty in assessing the resolution of these events as compared to other kinds. Further studies should be implemented to clarify this issue.

\section{Author contributions}

SF, IC, LL and MT were involved in the conception, design, analysis and interpretation of the data. $\mathrm{CB}$ and MT revised critically the manuscript, and SF, IC, LL, CB and MT reviewed the final version. All authors agree to be accountable for all aspects of the work.

\section{Funding}

This paper was not funded.

\section{Declaration of interests}

The authors have no relevant affiliations or financial involvement with any organization or entity with a financial interest in or financial conflict with the subject matter or materials discussed in the manuscript. This includes employment, consultancies, honoraria, stock ownership or options, expert testimony, grants or patents received or pending, or royalties.

\section{Reviewer disclosures}

Peer reviewers on this manuscript have no relevant financial or other relationships to disclose. 


\section{References}

Papers of special note have been highlighted as:

* of interest

** of considerable interest

1. EMA. Disabling and potentially permanent side effects lead to suspension or restrictions of quinolone and fluoroquinolone antibiotics. European Medicines Agency. www.ema.europa.eu/contact. Published 2018. Accessed April 29, 2019**

Takes part to the background from which we found the rationale of our paper

2. Tuccori M, Lapi F, Testi A, et al. Drug-Induced Taste and Smell Alterations. A Case/Non-Case Evaluation of an Italian Database of Spontaneous Adverse Drug Reaction Reporting. Drug Saf. 2011;34(10):849-59. doi:10.2165/11593120000000000-00000**

Takes part to the background from which we found the rationale of our paper

3. Black FO, Pesznecker S, Stallings V. Permanent Gentamicin Vestibulotoxicity. Otol Neurotol. 2004;25(4):559-69. doi:10.1097/00129492-200407000-00025

4. Guo J, Chai R, Li H, et al. Protection of Hair Cells from Ototoxic Drug-Induced Hearing Loss. Adv Exp Med Biol. 2019;1130:17-36. doi:10.1007/978-981-13-61234_2

5. Wilhelm M. Vancomycin. Mayo Clin Proc. 1991;66(11):1165-70. doi:10.1016/S00256196(12)65799-1

6. Doty RL, Bromley SM. Effects of drugs on olfaction and taste. Otolaryngol Clin North Am. 2004;37(6):1299-54. doi:10.1016/j.otc.2004.05.002

7. Thiermann F, Buchbauer G. Influence of drugs on smelling capacity. A review. Flavour Fragr J. 2017;32:147-58. doi:10.1002/ffj.3368

8. Lötsch J, Knothe C, Lippmann C, et al. Olfactory drug effects approached from human-derived data. Drug Discov Today. 2015;20(11):1398-406. doi:10.1016/j.drudis.2015.06.012

9. Agah E, Habibi A, Naderi $\mathrm{H}$, et al. Metronidazole-induced neurotoxicity presenting with sudden bilateral hearing loss, encephalopathy, and cerebellar dysfunction. Eur J Clin Pharmacol. 2017;73:249-50. doi:10.1007/s00228-016-2147-5

10. Jafari G, Hosseini SM, Akhondzadeh S. Sudden hearing loss subsequent to diarrhea: what is the missing link? DARU J Pharm Sci. 2014;22:15. doi:10.1186/2008-2231-22-15

11. Williams D, Laughli L, Lee Y. Minocycline: Possible Vestibular Side-Effects. Lancet. 
1974;304(7883):744-6.

12. Smith CJ, Sayles H, Mikuls TR, et al. Minocycline and doxycycline therapy in community patients with rheumatoid arthritis: prescribing patterns, patient-level determinants of use, and patient-reported side effects. Arthritis Res Ther. 2011;13(5):R168. doi:10.1186/ar3491

13. Seymour ML, Pereira FA. Survival of auditory hair cells. Cell Tissue Res. 2015;361:59-63. doi:10.1007/s00441-015-2152-5

14. Huth ME, Ricci AJ, Cheng AG. Mechanisms of Aminoglycoside Ototoxicity and Targets of Hair Cell Protection. Int $J$ Otolaryngol. 2011;2011(937861). doi:10.1155/2011/937861

15. Wang T, Glendinning J, Grushka M, et al. Drug-Induced Taste Disorders in Clinical Practice and Preclinical Safety Evaluation. Toxicol Sci. 2017;156(2):315-24. doi:10.1093/toxsci/kfw263

16. EMA. Guideline on good pharmacovigilance practices (GVP) - Annex I - Definitions (Rev 4). European Medicines Agency. www.ema.europa.eu. Published 2017. Accessed April 29, 2019.*

Guidelines on good pharmacovigilance practice (GVP) are fundamental for the evaluation of the characteristics of suspected adverse drug reactions we analyzed in the paper

17. Neuland C, Bitter T, Marschner $\mathrm{H}$, et al. Health-Related and Specific OlfactionRelated Quality of Life in Patients with Chronic Functional Anosmia or Severe Hyposmia. Laryngoscope. 2011;121 (4):867-72. doi:10.1002/lary.21387

18. Duxbury A, Oliver R, Pembetron M. Persistent impairment of taste associated with terbinafine. Br Dent J.2000;188(06):295-6. doi:10.1038/sj.bdj.4800461a

19. Şengeze N, Vedat Ali Y, Koyuncuoğlu HR, et al. Permanent Taste and Smell Disorders Induced by Clarithromycin: A Case Report. Turkish J Neurol. 2015;21:346. doi: $10.4274 /$ tnd. $13284^{*}$

Example of studies (together with reference 2) that evaluated the persistence of gustatory, auditory and olfactory adverse drug reactions to antibiotics

20. Coulston J, Balaratnam N. Irreversible sensorineural hearing loss due to clarithromycin. Postgr Med J. 2005;81:58-9. doi:10.1136/pgmj.2004.020412*

Examples of studies (together with reference 2) that evaluated the persistence of gustatory, auditory and olfactory adverse drug reactions to antibiotics 
Table 1: Number of overall and GOA reactions reported for antibiotic groups and organized by frequency of GOA reactions, according to their outcomes.

Table 2: Number of overall and GOA reactions reported for twenty selected antibiotics and organized by frequency of GOA reactions, according to their outcomes.

Table 3: Suspected GOA ADRs reported in Eudravigilance for twenty antibiotics compared to GOA ADRs labelled in the SPCs of originator medicinal products.

Figure 1: Data retrieval flow chart 
Table 1.

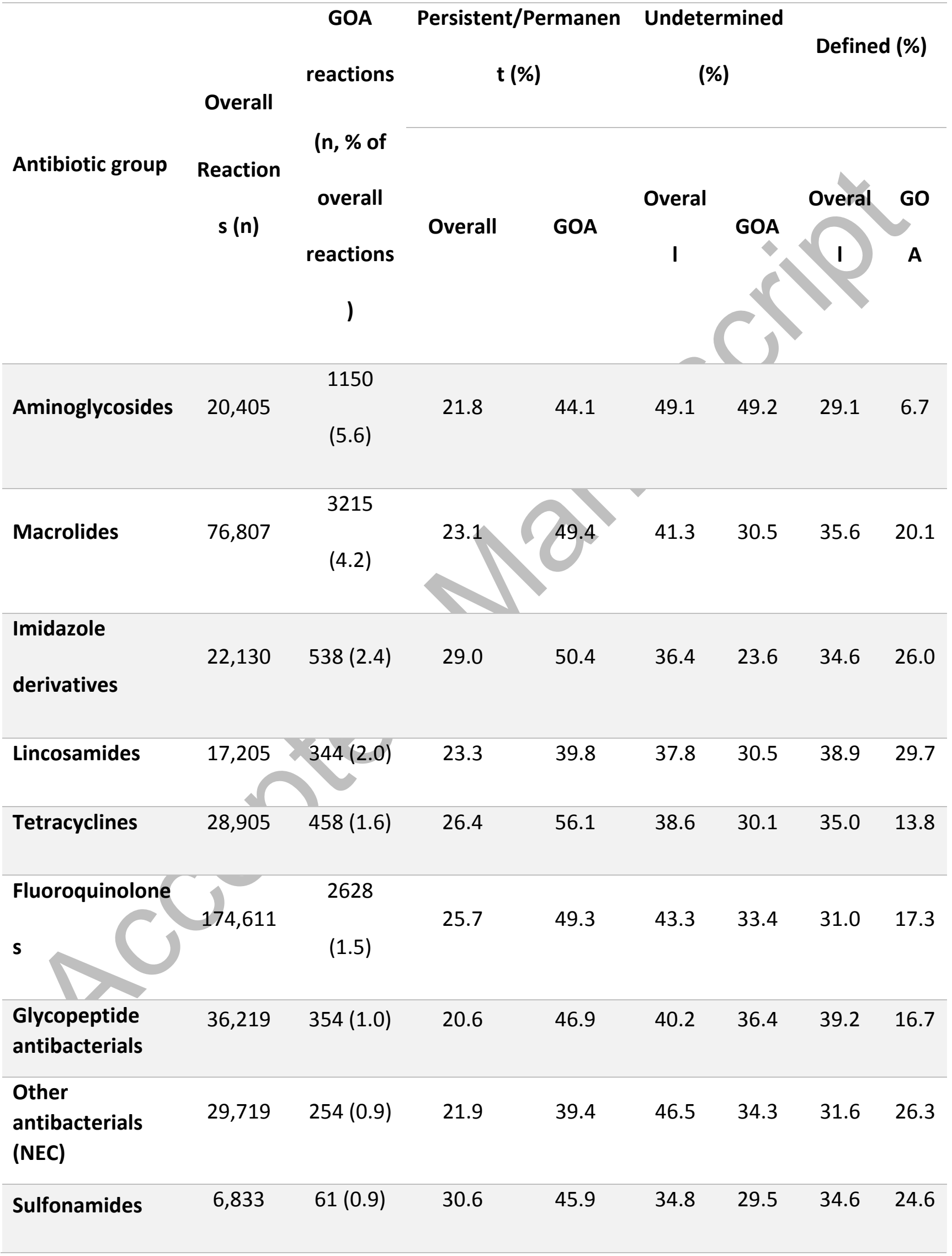


and

trimethoprim

Cephalosporins

$\begin{array}{lllllllll}\text { (Second } & 23,545 & 160(0.7) & 16.8 & 36.3 & 45.5 & 40.0 & 37.7 & 23.7\end{array}$

generation)

\begin{tabular}{lllllllll} 
Penicillins & 168,213 & $995(0.6)$ & 23.8 & 45.9 & 35.6 & 30.4 & 40.6 & 23.7 \\
\hline Carbapenems & 24,582 & $153(0.6)$ & 21.3 & 39.9 & 43.0 & 36.6 & 35.7 & 23.5 \\
\hline Nitrofuran & 14,413 & $89(0.6)$ & 33.9 & 50.6 & 29.6 & 31.5 & 36.5 & 17.9 \\
derivatives & & & & & & & &
\end{tabular}

Cephalosporins

$\begin{array}{lllllllll}\text { (Third } & 71,387 & 238(0.3) & 29.5 & 50.8 & 31.5 & 28.6 & 39.0 & 20.6\end{array}$

generation)

\begin{tabular}{|c|c|c|c|c|c|c|c|c|}
\hline Quinolones & 421 & $1(-)$ & 15.4 & - & 53.7 & - & 30.9 & - \\
\hline
\end{tabular}


Table 2.

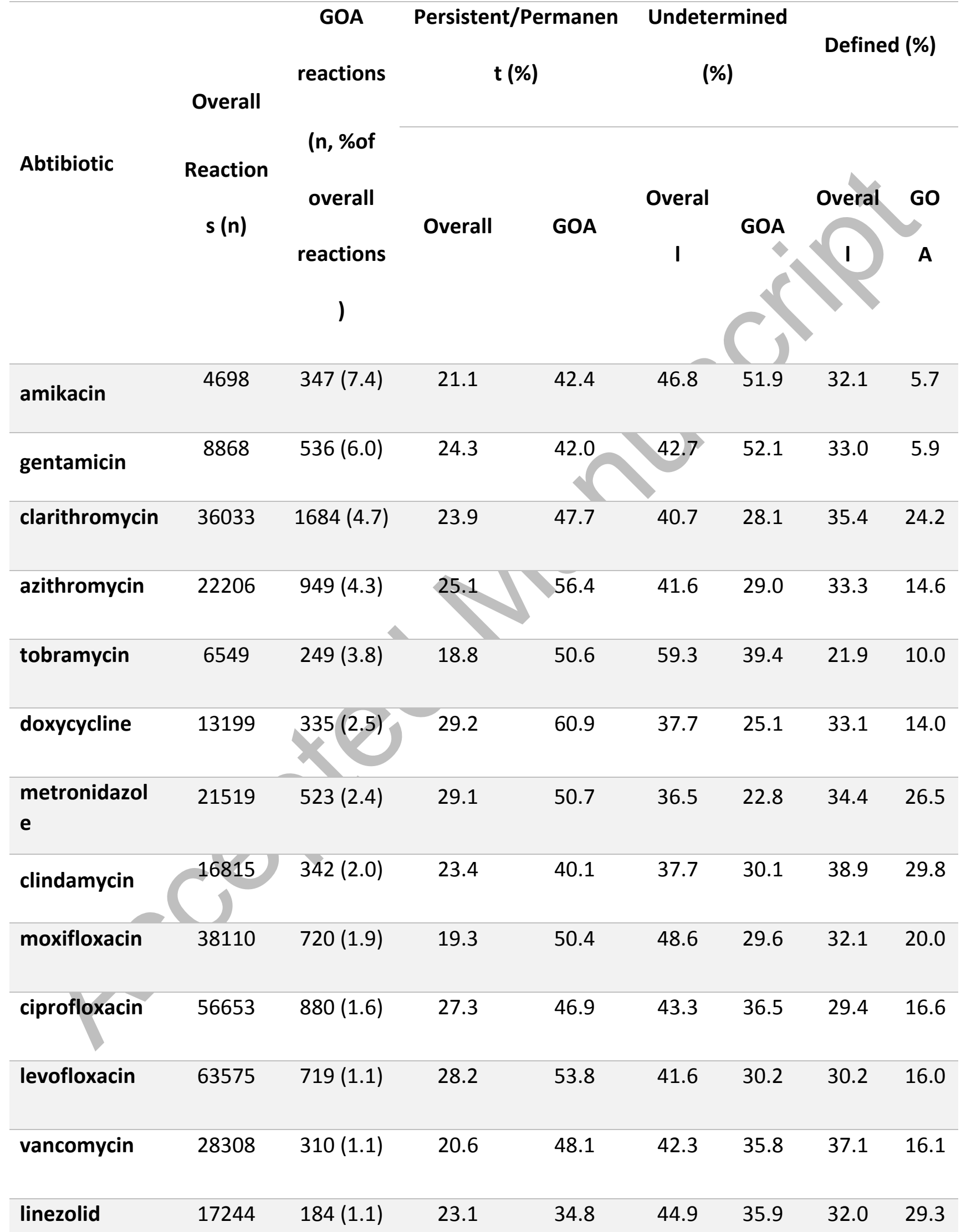




\begin{tabular}{|c|c|c|c|c|c|c|c|c|}
\hline cefuroxime & 14214 & 131 (0.9) & 17.0 & 34.4 & 43.9 & 40.5 & 39.1 & 25.1 \\
\hline \multicolumn{9}{|l|}{ imipenem and } \\
\hline \multicolumn{9}{|l|}{ cilastatin } \\
\hline minocycline & 9788 & $80(0.8)$ & 23.0 & 42.5 & 38.3 & 40.0 & 38.7 & 17.5 \\
\hline nitrofurantoin & 14371 & $89(0.6)$ & 34.0 & 50.6 & 29.6 & 31.4 & 36.4 & 18.0 \\
\hline meropenem & 11400 & $54(0.5)$ & 21.6 & 44.4 & 45.6 & 33.3 & 32.8 & 22.3 \\
\hline \multicolumn{9}{|l|}{ amoxicillin, } \\
\hline clavulanic acid & 112703 & $105(0.3)$ & 25.2 & 48.0 & 34.4 & 30.2 & 40.4 & 21.8 \\
\hline ceftriaxone & 39144 & $287(0.3)$ & 28.8 & 55.2 & 30.6 & 21.0 & 40.6 & 23.8 \\
\hline
\end{tabular}


Table 3.

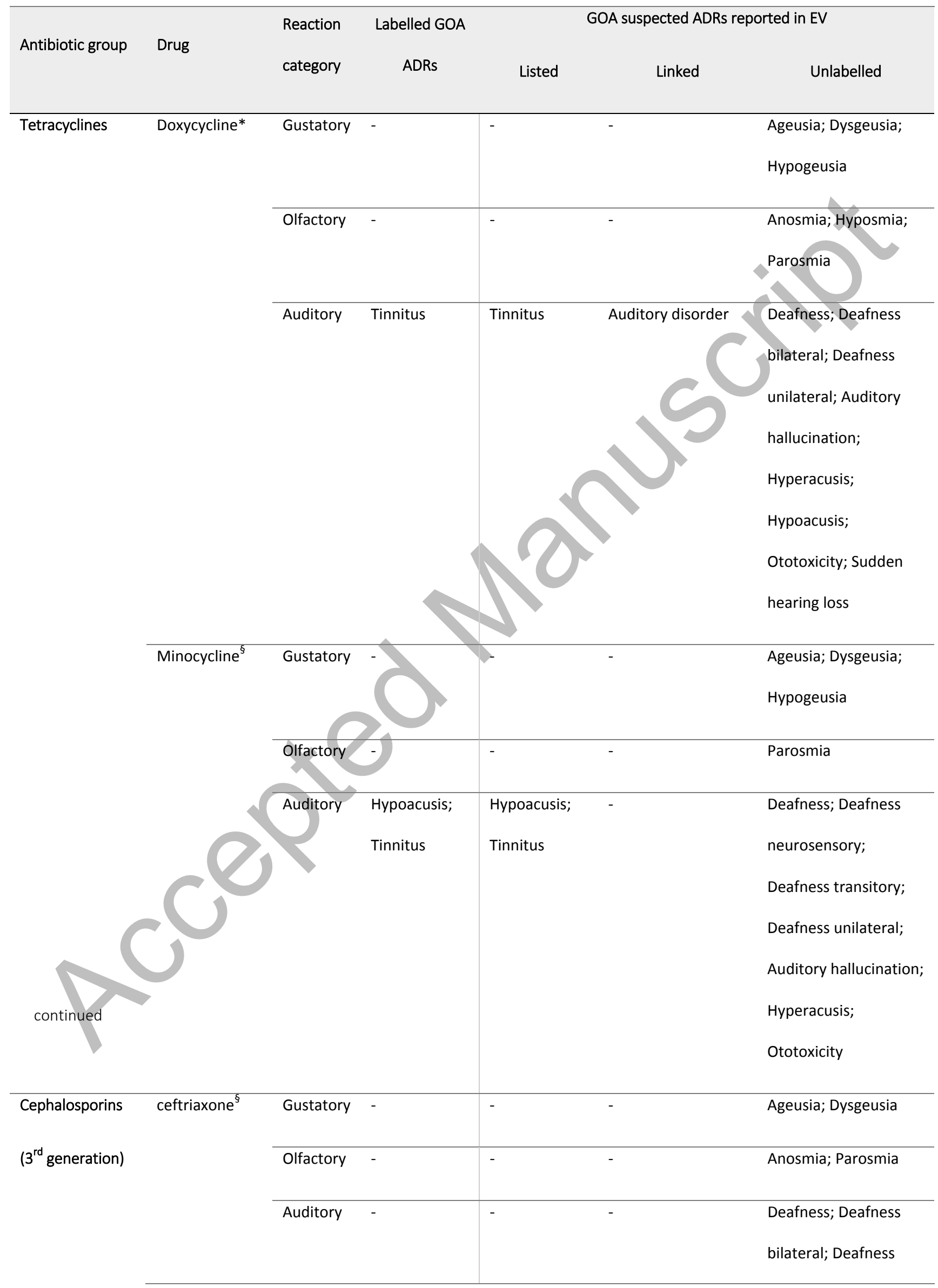




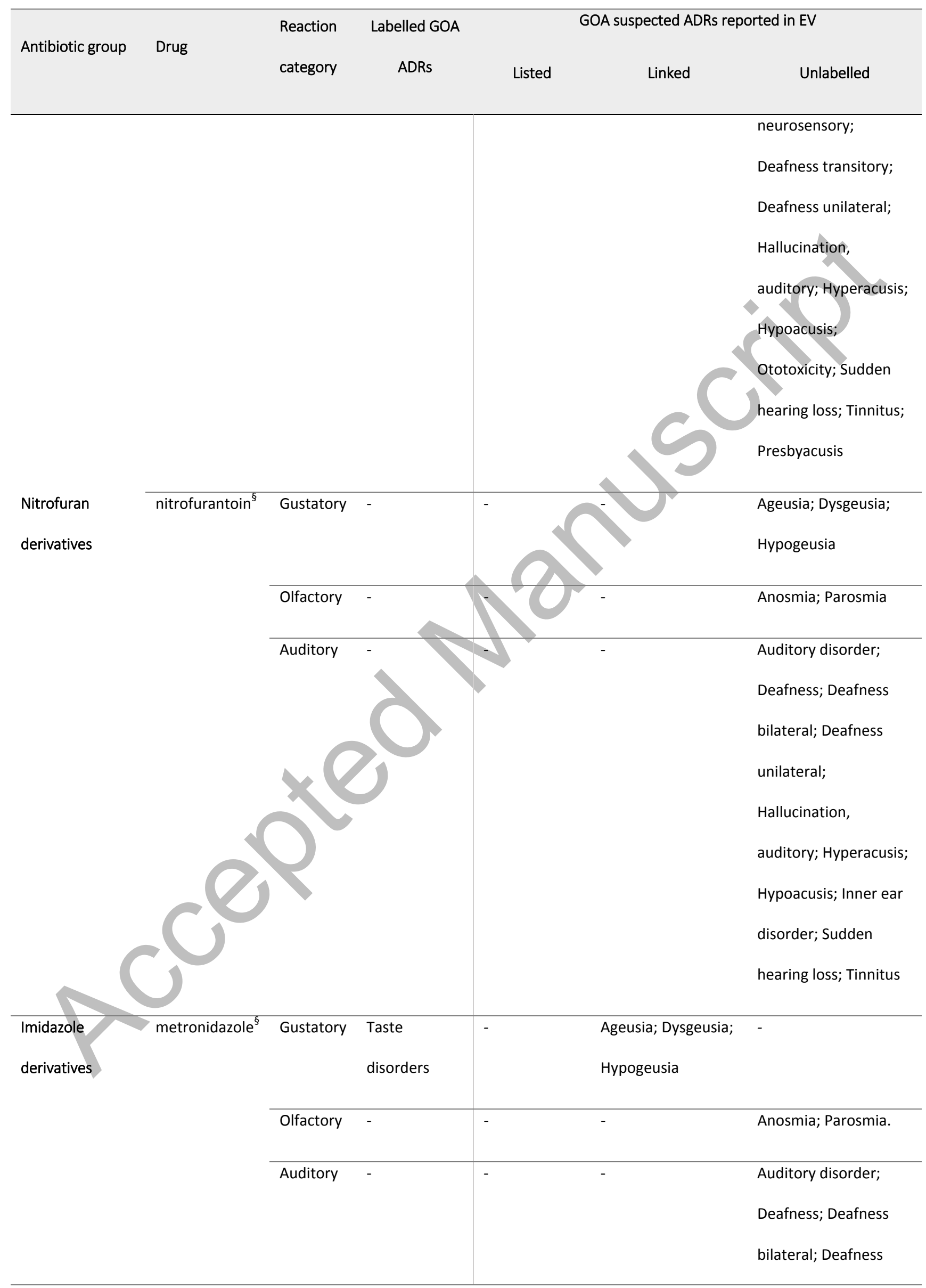




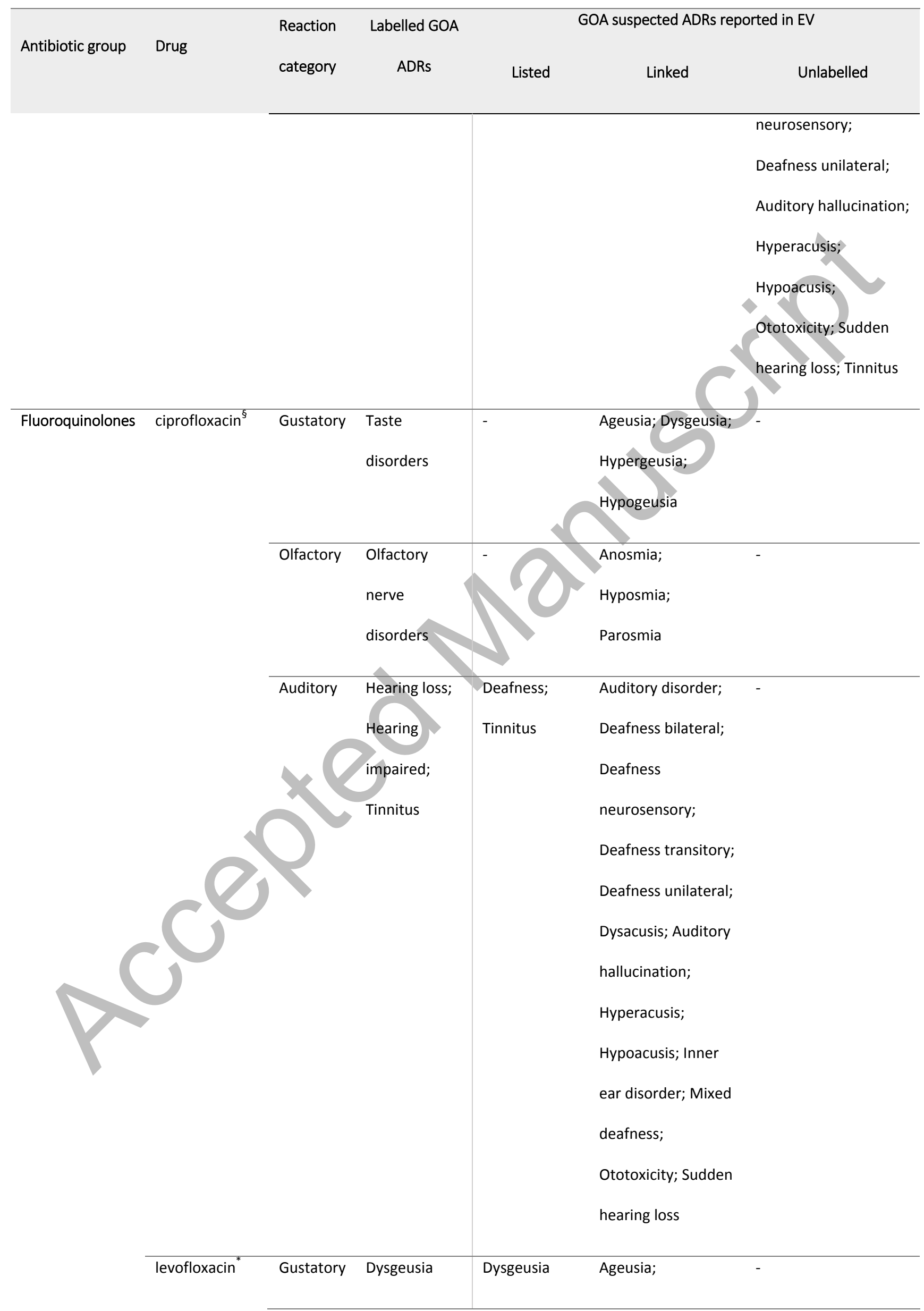




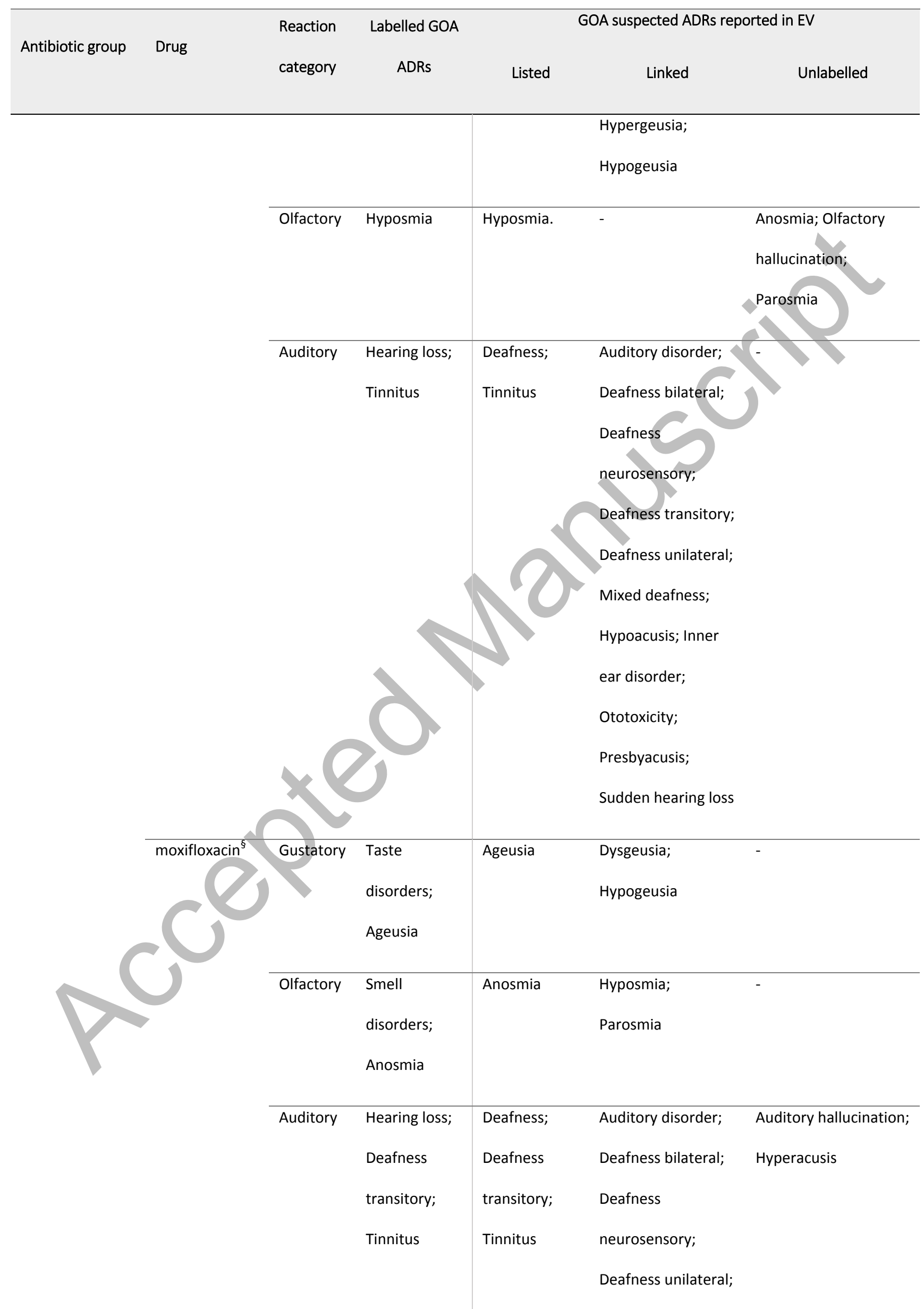




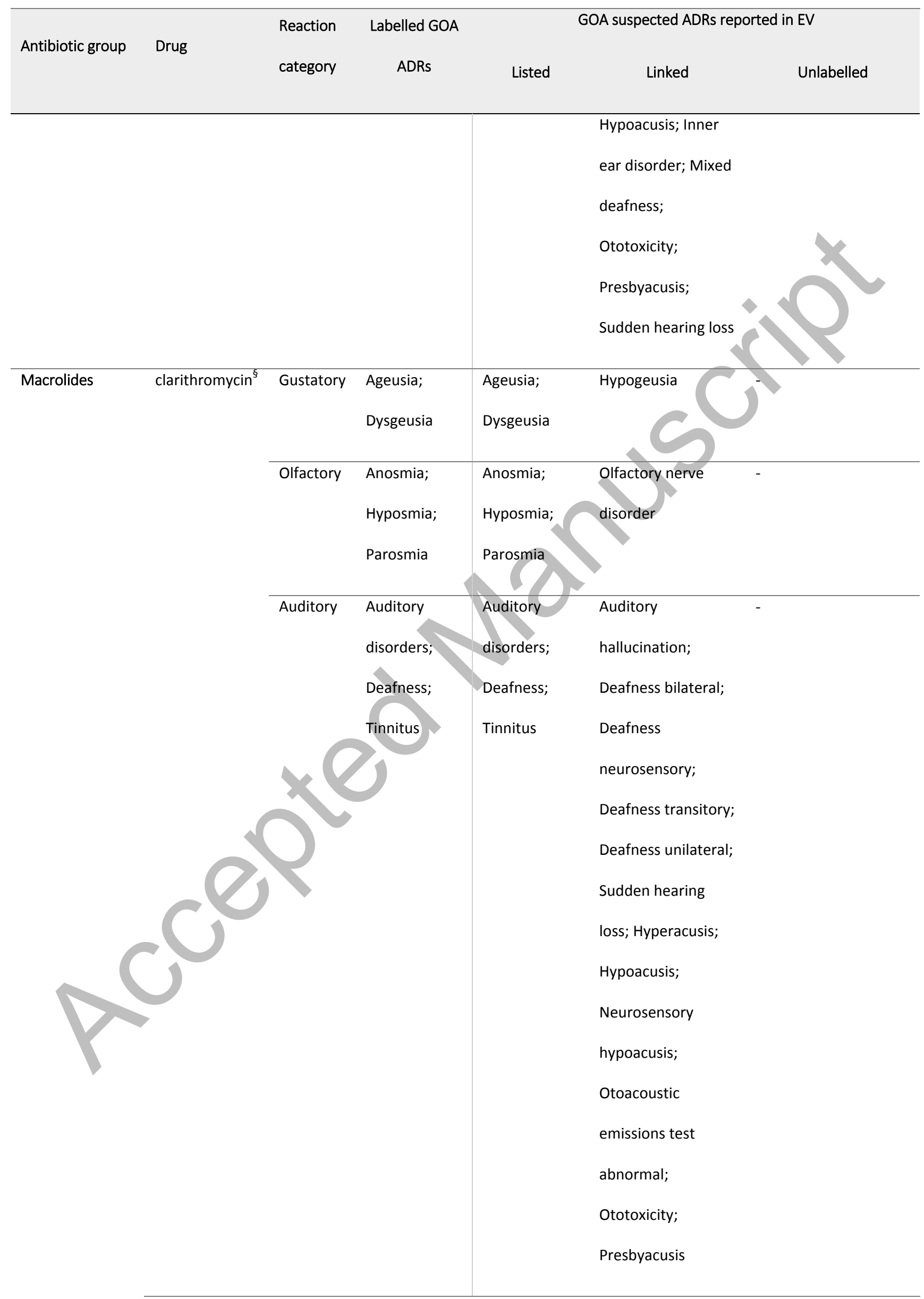




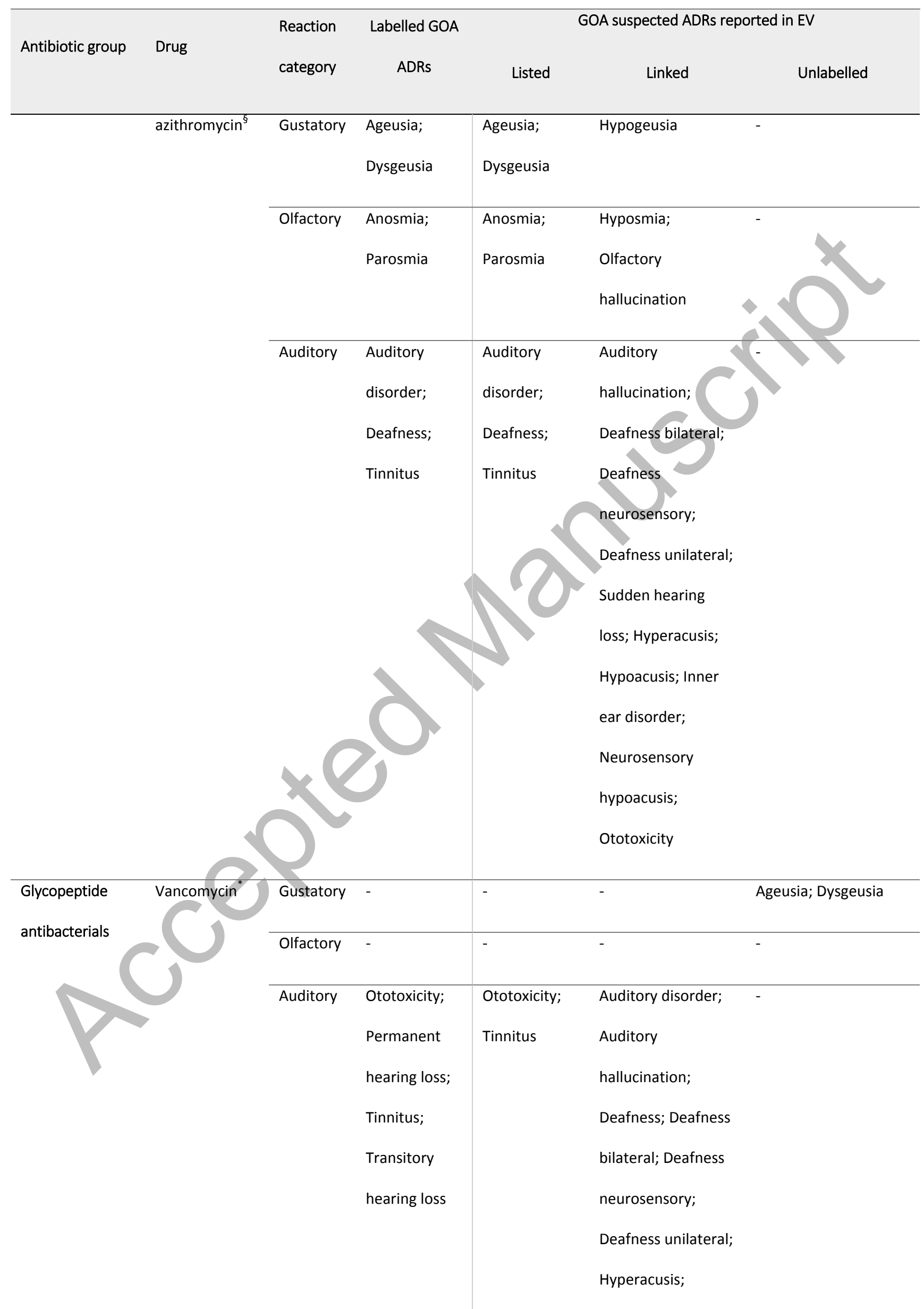




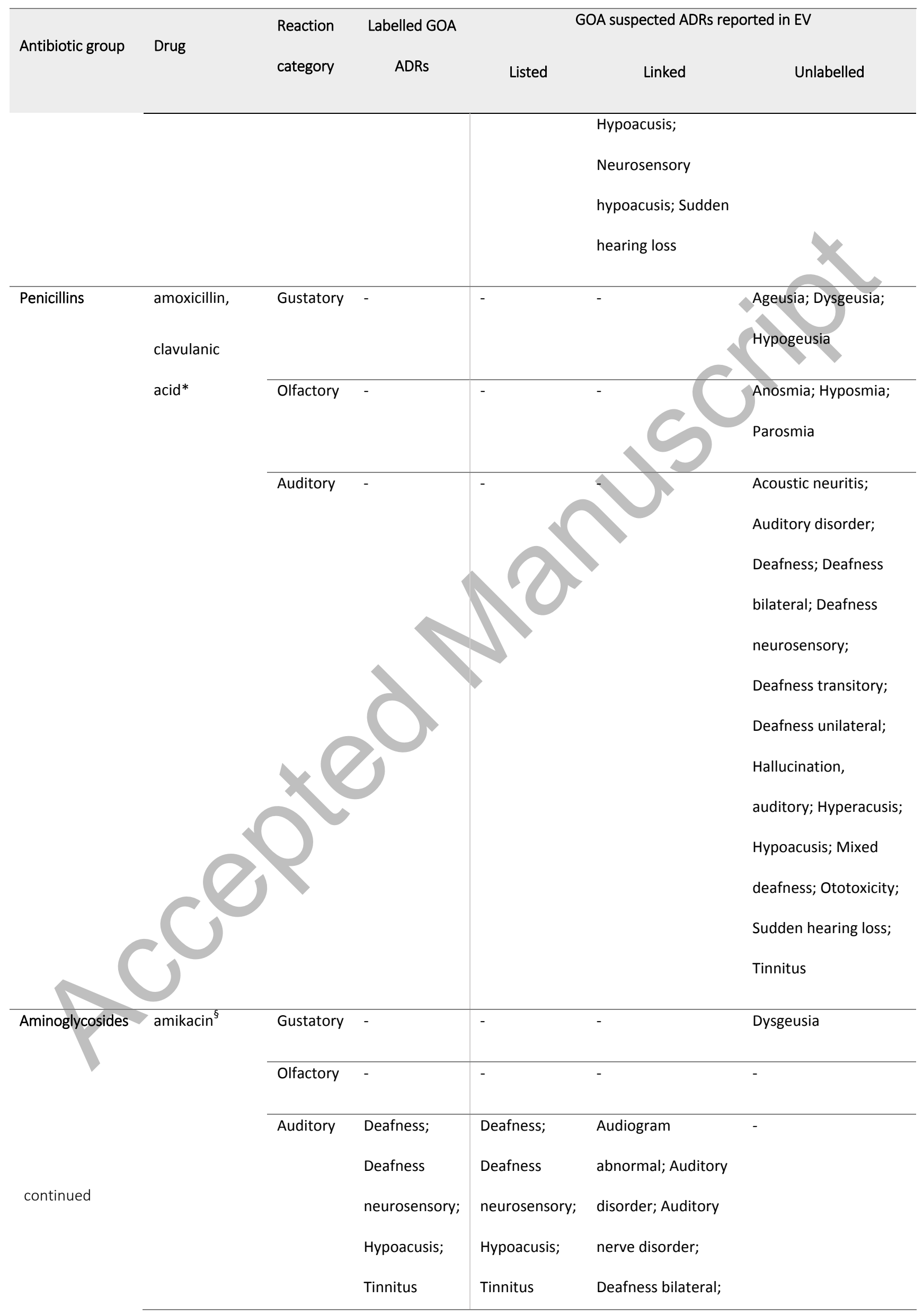




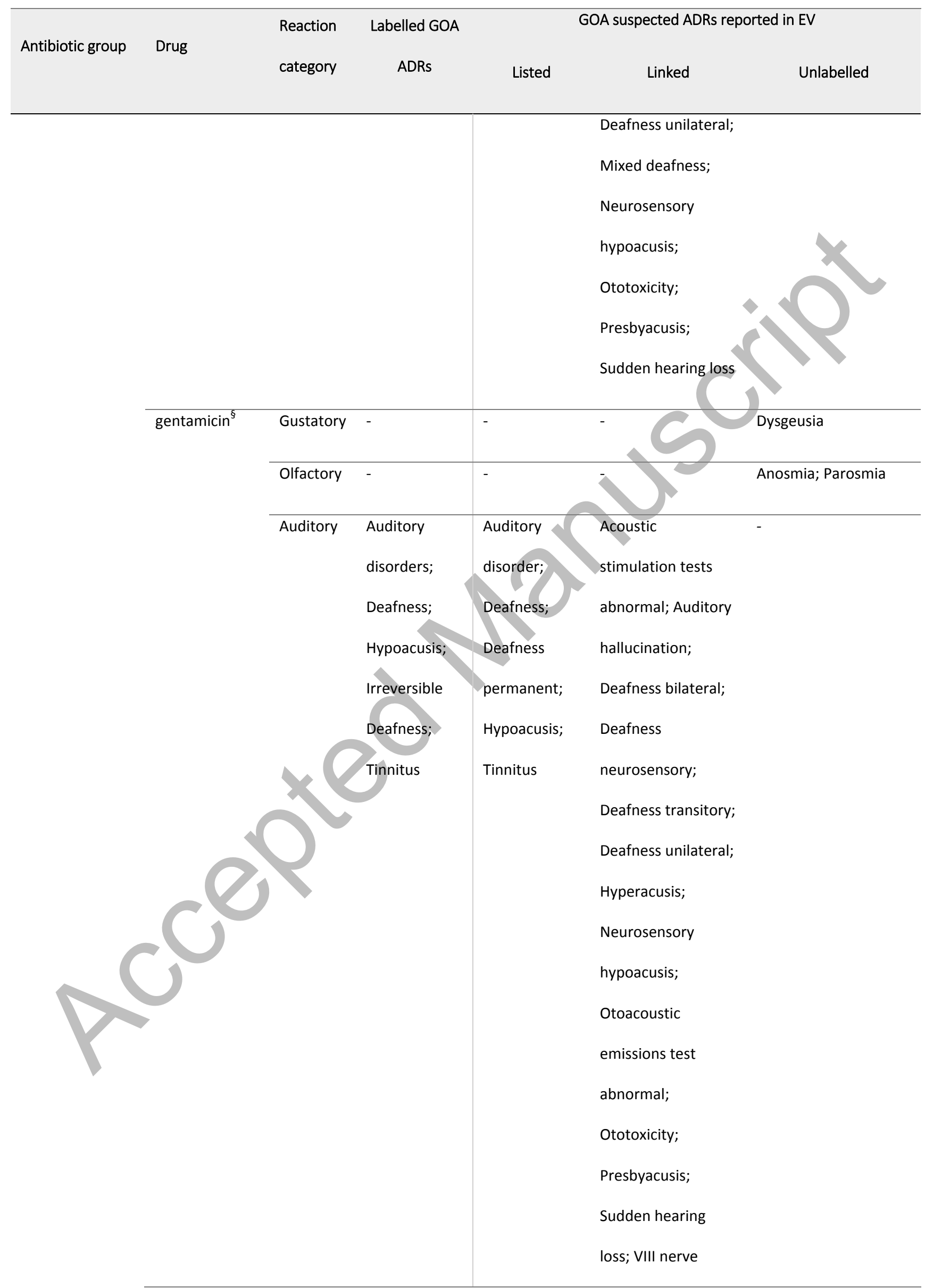




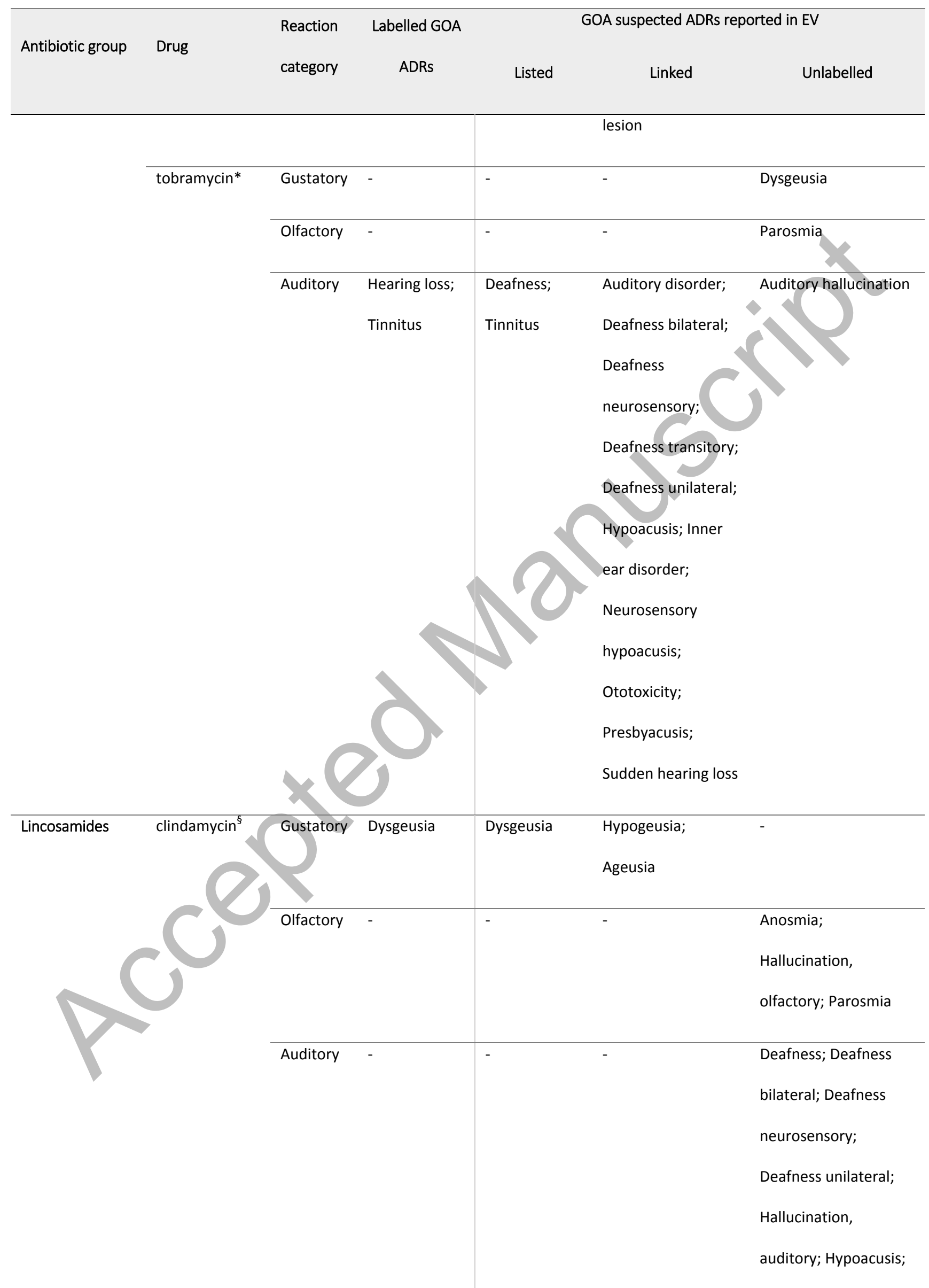




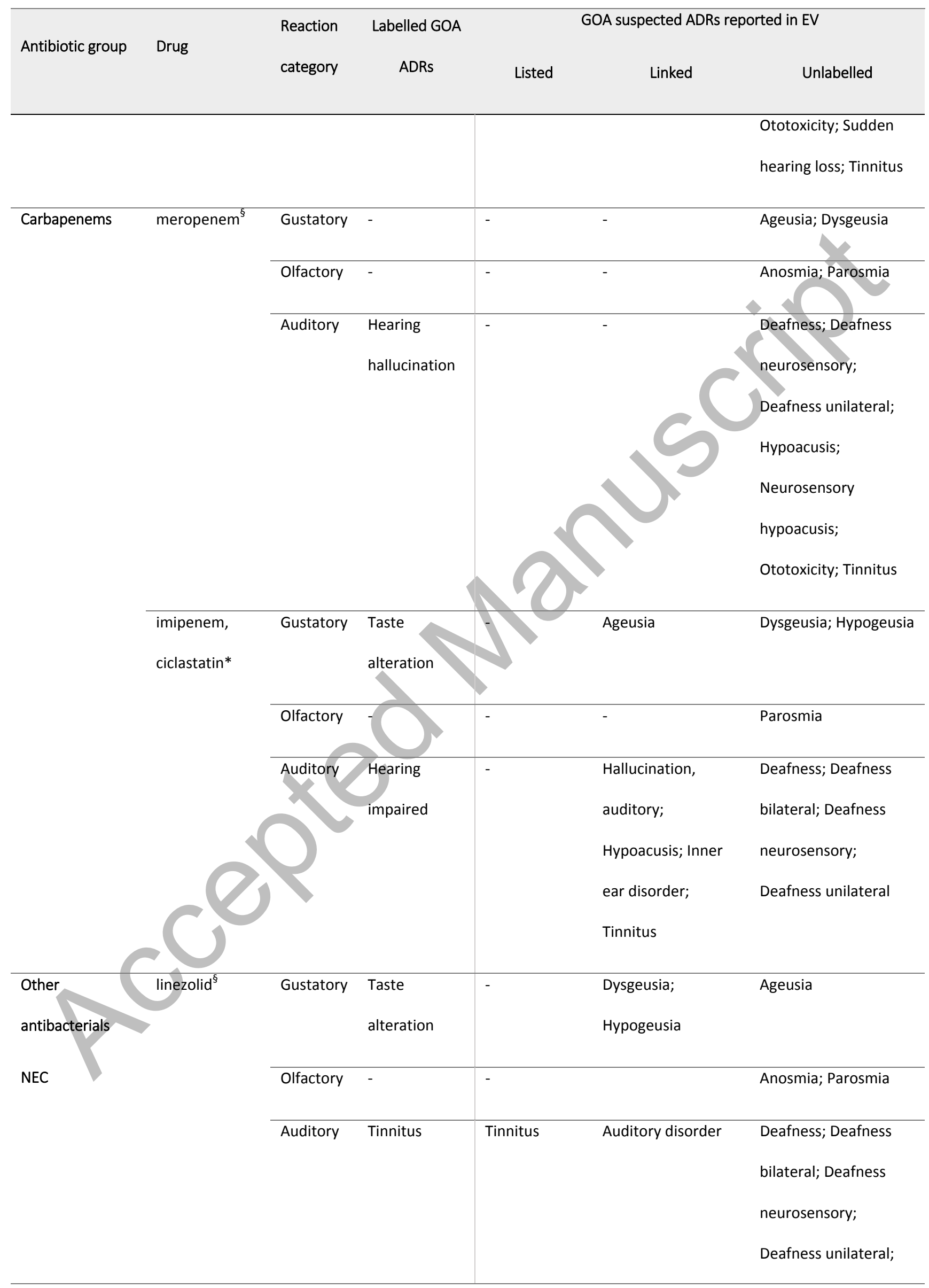




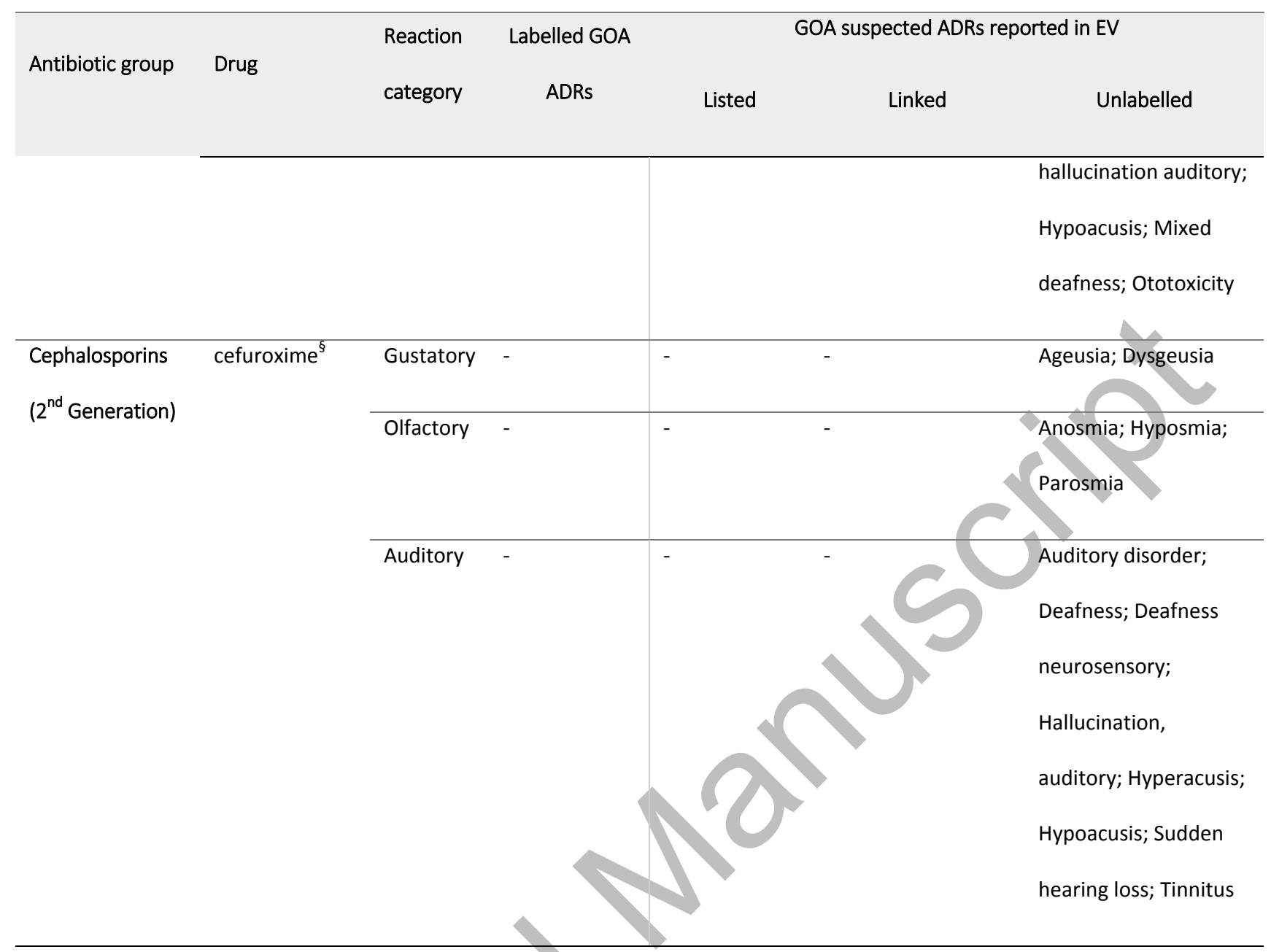

*: EMA source; §: AIFA source; NEC: not elsewhere classified 
Supplementary Table 5 a Tetracyclines and GOA reactions: outcomes and proportions (\% value) of each drug.

\begin{tabular}{lccccc}
\hline Tetracyclines & Persistent/permament & Undetermined & Defined & Total & \% \\
\hline doxycycline & $\mathbf{n})$ & $\mathbf{( n )}$ & $\mathbf{( n )}$ & $\mathbf{( n )}$ & \\
\hline chlortetracycline & 204 & 84 & 47 & 335 & 73.1 \\
\hline lymecicline & 0 & 0 & 0 & 0 & 0 \\
\hline metacycline & 2 & 4 & 0 & 6 & 1.3 \\
\hline oxitetracycline & 0 & 0 & 0 & 0 & 0 \\
\hline tetracycline & 0 & 2 & 0 & 2 & 0.4 \\
\hline minocycline & 9 & 7 & 1 & 17 & 3.7 \\
\hline tigecycline & 34 & 32 & 14 & 80 & 17.5 \\
\hline all drugs & 8 & 9 & 1 & 18 & 4.0 \\
\hline
\end{tabular}

Supplementary Table 5 b Cephalosporins (third generation) and GOA reactions: outcomes and proportions (\% value) of each drug.

\begin{tabular}{lccccc}
\hline $\begin{array}{l}\text { Cephalosporins } \\
\text { (third generation) }\end{array}$ & Persistent/permament & Undetermined & Defined & Total & $\%$ \\
\hline cefcapene & $\mathbf{n}$ ) & $\mathbf{( n )}$ & $\mathbf{( n )}$ & $\mathbf{( n )}$ & \\
\hline cefdinir & 3 & 0 & 0 & 3 & 1.3 \\
\hline cefditoren & 2 & 3 & 1 & 6 & 2.5 \\
\hline cefixime & 0 & 1 & 1 & 2 & 0.8 \\
\hline cefodizime & 8 & 6 & 4 & 18 & 7.6 \\
\hline cefoperazone & 0 & 0 & 0 & 0 & 0 \\
\hline cefoperazone, sulbactam & 0 & 0 & 0 & 0 & 0 \\
\hline cefotaxime & 7 & 0 & 1 & 8 & 3.4 \\
\hline cefpiramide & 9 & 3 & 6 & 18 & 7.6 \\
\hline cefpodoxime & 0 & 0 & 0 & 0 & 0 \\
\hline cefsulodin & 15 & 7 & 2 & 24 & 10.1 \\
\hline ceftazidime & 0 & 0 & 0 & 0 & 0 \\
\hline ceftazidime, avibactam & 15 & 15 & 7 & 37 & 15.5 \\
\hline
\end{tabular}




\begin{tabular}{lccccc}
\hline cefteram & 0 & 0 & 0 & 0 & 0 \\
\hline ceftibuten & 4 & 10 & 1 & 15 & 6.3 \\
\hline ceftizoxime & 0 & 1 & 1 & 2 & 0.8 \\
\hline ceftriaxone & 58 & 22 & 25 & 105 & 44.1 \\
\hline all drugs & 121 & 68 & 49 & 238 & 100
\end{tabular}

Supplementary Table 5 c Nitrofuran derivatives and GOA reactions: outcomes and proportions (\% value) of each drug.

\begin{tabular}{|c|c|c|c|c|c|}
\hline Nitrofuran derivatives & $\begin{array}{l}\text { Persistent/permame } \\
\text { nt } \\
\text { (n) }\end{array}$ & $\begin{array}{c}\text { Undetermine } \\
\text { d } \\
\text { (n) }\end{array}$ & $\begin{array}{l}\text { Define } \\
\quad d \\
\text { (n) }\end{array}$ & $\begin{array}{l}\text { Tota } \\
\text { I } \\
\text { (n) }\end{array}$ & $\%$ \\
\hline nitrofurantoin & 45 & 28 & 16 & 89 & $\begin{array}{c}10 \\
0\end{array}$ \\
\hline $\begin{array}{l}\text { nitrofurantoin, pyridoxine } \\
\text { hydrochloride }\end{array}$ & & 0 & 0 & 0 & 0 \\
\hline all drugs & 45 & 28 & 16 & 89 & $\begin{array}{c}10 \\
0\end{array}$ \\
\hline
\end{tabular}

Supplementary Table 5 d Imidazole derivatives and GOA reactions: outcomes and proportions (\% value) of each drug.

\begin{tabular}{lccccc}
\hline Imidazole Derivatives & Persistent/permament & Undetermined & Defined & Total & \% \\
& $(\mathbf{n})$ & $\mathbf{( n )}$ & $\mathbf{( n )}$ & $\mathbf{( n )}$ & \\
\hline metronidazole & 265 & 119 & 139 & 523 & 97.2 \\
\hline tinidazole & 4 & 7 & 1 & 12 & 2.2 \\
\hline ornidazole & 2 & 1 & 0 & 3 & 0.6 \\
\hline all drugs & 271 & 127 & 140 & 538 & 100
\end{tabular}

Supplementary Table 5 e Fluoroquinolones and GOA reactions: outcomes and proportions (\% value) of each drug.

\begin{tabular}{cccccc}
\hline Fluoroquinolones & Persistent/permament & Undetermined & Defined & Total & $\%$
\end{tabular}




\begin{tabular}{lccccc}
\hline ofloxacin & 88 & 102 & 32 & 222 & 8.4 \\
\hline ciprofloxacin & 413 & 321 & 146 & 880 & 33.5 \\
\hline pefloxacin & 0 & 0 & 0 & 0 & 0 \\
\hline enoxacin & 1 & 2 & 2 & 5 & 0.2 \\
\hline norfloxacin & 18 & 13 & 9 & 40 & 1.5 \\
\hline lomefloxacin & 6 & 1 & 1 & 8 & 0.3 \\
\hline rufloxacin & 0 & 1 & 0 & 1 & 0 \\
\hline grepafloxacin & 6 & 4 & 4 & 14 & 0.5 \\
\hline levofloxacin & 387 & 217 & 115 & 719 & 27.4 \\
\hline trovafloxacin & 10 & 1 & 1 & 12 & 0.5 \\
\hline moxifloxacin & 363 & 213 & 144 & 720 & $\mathbf{2 7 . 4}$ \\
\hline prulifloxacin & 4 & 3 & 0 & 7 & 0.3 \\
\hline all drugs & 1296 & 878 & 454 & 2628 & 100 \\
\hline
\end{tabular}

Supplementary Table 5 f Macrolides and GOA reactions: outcomes and proportions (\% value) of each drug.

\begin{tabular}{lccccc}
\hline Macrolides & Persistent/permament & Undetermined & Defined & Total & \% \\
& $(\mathbf{n})$ & $\mathbf{( n )}$ & $\mathbf{( n )}$ & $\mathbf{( n )}$ & \\
\hline erythromycin & 58 & 59 & 57 & 174 & 5.4 \\
\hline spiramycin & 9 & 4 & 12 & 25 & 0.8 \\
\hline roxithromycin & 146 & 164 & 15 & 325 & 10.1 \\
\hline clarithromycin & 803 & 474 & 407 & 1684 & $\mathbf{5 2 . 4}$ \\
\hline azithromycin & 535 & 275 & 139 & 949 & $\mathbf{2 9 . 5}$ \\
\hline telithromycin & 36 & 5 & 17 & 58 & 1.8 \\
\hline all drugs & 1587 & 981 & 647 & 3215 & 100 \\
\hline
\end{tabular}

Supplementary Table $5 \mathrm{~g}$ Glycopeptide antibacterials and GOA reactions: outcomes and proportions (\% value) of each drug. 


\begin{tabular}{lccccc}
\hline Glycopeptide antibacterials & Persistent/permament & Undetermined & Defined & Total & \% \\
& $(\mathbf{n})$ & $(\mathbf{n})$ & $\mathbf{( n )}$ & $\mathbf{( n )}$ & \\
\hline vancomycin & 149 & 111 & 50 & 310 & 87.6 \\
\hline teicoplanin & 17 & 15 & 7 & 39 & 11.0 \\
\hline telavancin & 0 & 3 & 2 & 5 & 1.4 \\
\hline dalbavancin & 0 & 0 & 0 & 0 & 0 \\
oritavancin & 0 & 0 & 0 & 0 & 0 \\
\hline all drugs & 166 & 129 & 59 & 354 & 100 \\
\hline
\end{tabular}

Supplementary Table $5 \mathbf{h}$ Sulfonamides and trimethoprim and GOA reactions: outcomes and proportions (\% value) of each drug.

\begin{tabular}{|c|c|c|c|c|c|}
\hline $\begin{array}{l}\text { Sulfonamides and } \\
\text { trimethoprim }\end{array}$ & $\begin{array}{c}\text { Persistent/permamen } \\
\text { t } \\
\text { (n) }\end{array}$ & $\begin{array}{l}\text { d } \\
\text { (n) }\end{array}$ & $\begin{array}{l}\text { Define } \\
\text { d } \\
\text { (n) }\end{array}$ & $\begin{array}{l}\text { Tota } \\
\text { I } \\
\text { (n) }\end{array}$ & $\%$ \\
\hline trimethoprim & 22 & 13 & 14 & 49 & $\begin{array}{c}80 . \\
4\end{array}$ \\
\hline sulfafurazole & 0 & 0 & 0 & 0 & 0 \\
\hline sufamethizole & 0 & 0 & 0 & 0 & 0 \\
\hline sulfanilamide & 0 & 1 & 0 & 1 & 1.6 \\
\hline sulfamethoxazole & 6 & 4 & 1 & 11 & $\begin{array}{c}18 . \\
0\end{array}$ \\
\hline sulfametrole, trimethoprim & 0 & 0 & 0 & 0 & 0 \\
\hline all drugs & 28 & 18 & 15 & 61 & 100 \\
\hline
\end{tabular}

Supplementary Table 5 i Penicillins and GOA reactions: outcomes and proportions (\% value) of each drug.

Penicillins

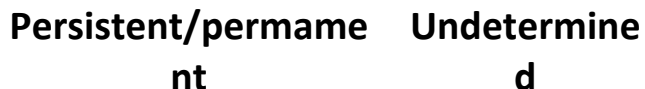

(n)

$\begin{array}{lll}3 & 8 & 2 \\ 0 & 0 & 0\end{array}$

ampicillin

pivampicillin

carbenicillin

Tot
Defined al

(n)

(n)

$\begin{array}{ll}2 & 13 \\ 0 & 0\end{array}$

13

1

\section{3}

0

0.1 


\begin{tabular}{|c|c|c|c|c|c|}
\hline amoxicillin & 230 & 108 & 91 & 429 & 43.2 \\
\hline bacampicillin & 1 & 0 & 0 & 1 & 0.1 \\
\hline pivmecillinam & 7 & 0 & 2 & 9 & 0.9 \\
\hline mezlocillin & 0 & 1 & 0 & 1 & 0.1 \\
\hline piperacillin & 6 & 3 & 5 & 14 & 1.4 \\
\hline ticarcillin & 0 & 2 & 0 & 2 & 0.2 \\
\hline temocillin & 0 & 0 & 0 & 0 & 0 \\
\hline benzathine benzylpenicillin & 1 & 2 & 1 & 4 & 0.4 \\
\hline $\begin{array}{l}\text { benzathine benzylpenicillin, } \\
\text { lidocaine hydrochloride }\end{array}$ & 0 & 0 & & 0 & 0 \\
\hline $\begin{array}{l}\text { benzathine benzylpenicillin, } \\
\text { procaine benzylpenicillin } \\
\text { monohydrate }\end{array}$ & 0 & 1 & 0 & 1 & 0.1 \\
\hline $\begin{array}{l}\text { benzathine } \\
\text { phenoxymethylpenicillin }\end{array}$ & 0 & & 1 & 1 & 0.1 \\
\hline benzylpenicillin & 4 & 4 & 7 & 15 & 1.5 \\
\hline penamecillin & 0 & 0 & 0 & 0 & 0 \\
\hline phenoxymethylpenicillin & 25 & 15 & 13 & 53 & 5.3 \\
\hline procaine benzylpenicillin & 4 & 7 & 8 & 19 & 1.9 \\
\hline cloxacillin & 4 & 3 & 1 & 8 & 0.8 \\
\hline dicloxacillin & & 0 & 0 & 4 & 0.4 \\
\hline flucloxacillin & 27 & 5 & 6 & 38 & 3.8 \\
\hline oxacillin & 0 & 0 & 0 & 0 & 0 \\
\hline ampicillin, sulbactam & 7 & 3 & 7 & 17 & 1.7 \\
\hline amoxicillin, clavulanic acid & 114 & 108 & 65 & 287 & 28.9 \\
\hline sultamicillin & 3 & 8 & 4 & 15 & 1.5 \\
\hline piperacillin, tazobactam & 14 & 24 & 23 & 61 & 6.1 \\
\hline $\begin{array}{l}\text { ampicillin trihydrate, } \\
\text { flucloxacillin sodium }\end{array}$ & 2 & 0 & 0 & 2 & 0.2 \\
\hline ampicillin, cloxacillin & 0 & 0 & 0 & 0 & 0 \\
\hline all drugs & 457 & 302 & 236 & 995 & 100 \\
\hline
\end{tabular}


Supplementary Table 5 j Aminoglycosides and GOA reactions: outcomes and proportions (\% value) of each drug.

\begin{tabular}{lccccc}
\hline Aminoglycosides & Persistent/permament & Undetermined & Defined & Total & $\%$ \\
\hline amikacin & $(\mathbf{n})$ & $(\mathbf{n})$ & $(\mathbf{n})$ & $(\mathbf{n})$ & \\
\hline gentamicin & 147 & 180 & 20 & 347 & 30.2 \\
\hline neomycin & 225 & 279 & 32 & 536 & 46.6 \\
\hline tobramycin & 9 & 9 & 0 & 18 & 1.5 \\
\hline all drugs & 126 & 98 & 25 & 249 & $\mathbf{2 1 . 7}$ \\
\hline & 507 & 566 & 77 & 1150 & 100 \\
\hline
\end{tabular}

Supplementary Table 5 k Lincosamides and GOA reactions: outcomes and proportions (\% value) of each drug.

\begin{tabular}{lccccc}
\hline Lincosamides & Persistent/permament & Undetermined & Defined & Total & $\%$ \\
\hline clindamycin & $(\mathbf{n})$ & $(\mathbf{n})$ & $(\mathbf{n})$ & (n) & \\
\hline lincomycin & 137 & 103 & 102 & 342 & 99.4 \\
\hline all drugs & 0 & 2 & 0 & 2 & 0.6 \\
\hline
\end{tabular}


Supplementary Table 5 I Carbapenems and GOA reactions: outcomes and proportions (\% value) of each drug.

\begin{tabular}{lccccc}
\hline Carbapenems & Persistent/permament & Undetermined & Defined & Total & \% \\
& $(\mathbf{n})$ & $(\mathbf{n})$ & $\mathbf{( n )}$ & $\mathbf{( n )}$ & \\
\hline meropenem & 24 & 18 & 12 & 54 & $\mathbf{3 5 . 3}$ \\
\hline ertapenem & 2 & 6 & 12 & 20 & 13.1 \\
\hline doripenem & 1 & 0 & 1 & 2 & 1.3 \\
\hline imipenem and cilastatin & 34 & 32 & 11 & 77 & $\mathbf{5 0 . 3}$ \\
\hline all drugs & 61 & 56 & 36 & 153 & 100
\end{tabular}

Supplementary Table 5 m Other antibacterials and GOA reactions: outcomes and proportions (\% value) of each drug.

Other Antibacterials (NEC) Persistent/permament Undetermined Defined Total

\begin{tabular}{lccccc} 
& $(\mathbf{n})$ & $(\mathbf{n})$ & $(\mathbf{n})$ & $(\mathbf{n})$ & $\%$ \\
\hline fosfomycin & 19 & 6 & 10 & 35 & 13.8 \\
\hline clofoctol & 0 & 0 & 0 & 0 & 0 \\
\hline methenamine & 0 & 2 & 0 & 2 & 0.8 \\
\hline nitroxoline & 1 & 0 & 0 & 1 & 0.4 \\
\hline linezolid & 64 & 66 & 54 & 184 & 72.4 \\
\hline daptomycin & 14 & 12 & 3 & 29 & 11.4 \\
\hline bacitracin & 2 & 1 & 0 & 3 & 1.2 \\
\hline all drugs & 100 & 87 & 67 & 254 & 100
\end{tabular}

NEC: not elsewhere classified

Supplementary Table 5 n Cephalosporins (Second generation) and GOA reactions: outcomes and proportions (\% value) of each drug.

\section{Cephalosporins (Second Generation)}

\section{Persistent/permame nt}

$\begin{array}{ccc}\text { Define } & \text { Tota } \\ \text { d } & \text { I }\end{array}$



(n)
(n)
(n)
(n)

\begin{tabular}{lccccc}
\hline cefaclor & 7 & 9 & 4 & 20 & 12. \\
\hline cefamandole & 0 & 0 & 0 & 0 & 0 \\
\hline cefminox & 0 & 0 & 0 & 0 & 0 \\
\hline cefonicid & 0 & 0 & 0 & 0 & 0 \\
\hline cefotiam & 2 & 0 & 1 & 3 & 1.9 \\
\hline cefoxitin & 3 & 1 & 0 & 4 & 2.5 \\
\hline cefprozil & 1 & 1 & 0 & 2 & 1.2 \\
\hline cefuroxime & 45 & 53 & 33 & 131 & $\mathbf{8 1 .}$ \\
\hline all drugs & 58 & 64 & 38 & 160 & 100 \\
\hline
\end{tabular}

Supplementary Table 2. Dictionary of drugs belonging to the ATC class J01 (Antibacterials for systemic use) for which at least a report of suspected ADR was reported in the Eudravigilance database.

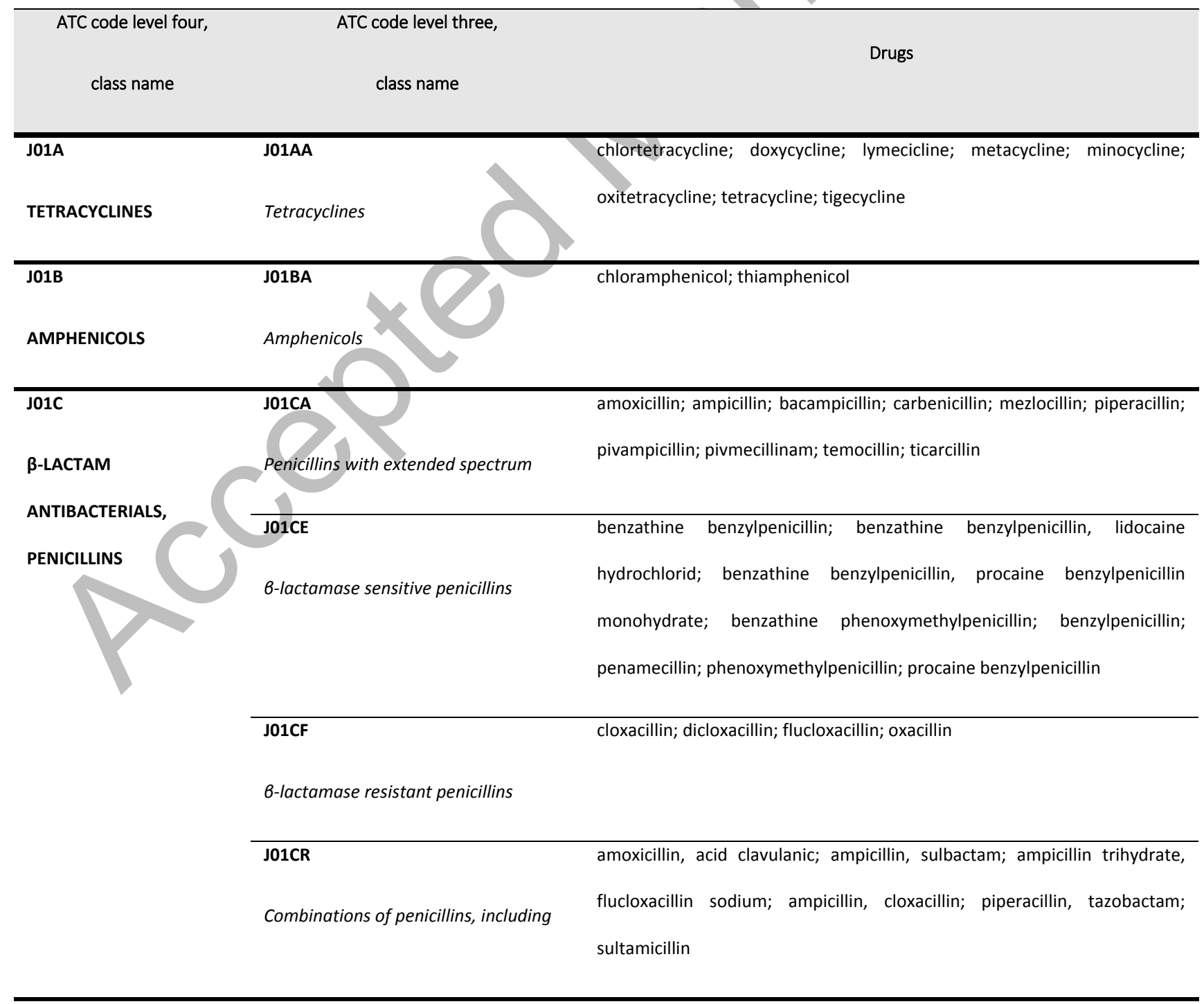




\begin{tabular}{|c|c|c|}
\hline J01D & J01DB & cefadroxil; cefalexin; cefalotin; cefapirin; cefatrizine; cefazolin; cefradine; \\
\hline OTHER $\beta$-LACTAM & First-generation cephalosporins & ceftezole \\
\hline ANTIBACTERIALS & $\begin{array}{l}\text { J01DC } \\
\text { Second-generation cephalosporins }\end{array}$ & $\begin{array}{l}\text { cefaclor; cefamandole; cefminox; cefonicid; cefotiam; cefoxitin; cefprozil; } \\
\text { cefuroxime }\end{array}$ \\
\hline & $\begin{array}{l}\text { J01DD } \\
\text { Third-generation cephalosporins }\end{array}$ & $\begin{array}{l}\text { cefcapene; cefdinir; cefditoren; cefixime; cefodizime; cefoperazone; } \\
\text { cefoperazone, sulbactam; cefotaxime; cefpiramide; cefpodoxime; } \\
\text { cefsulodin; ceftazidime; ceftazidime, avibactam; cefteram; ceftibuten; } \\
\text { ceftizoxime; ceftriaxone }\end{array}$ \\
\hline & J01DE & cefepime; cefpirome \\
\hline
\end{tabular}

Fourth-generation cephalosporins

J01DF aztreonam

Monobactams

J01DH ertapenem; meropenem; doripenem; imipenem, cilastatin

Carbapenems

J01DI ceftobiprole; ceftaroline;

Other cephalosporins and penems

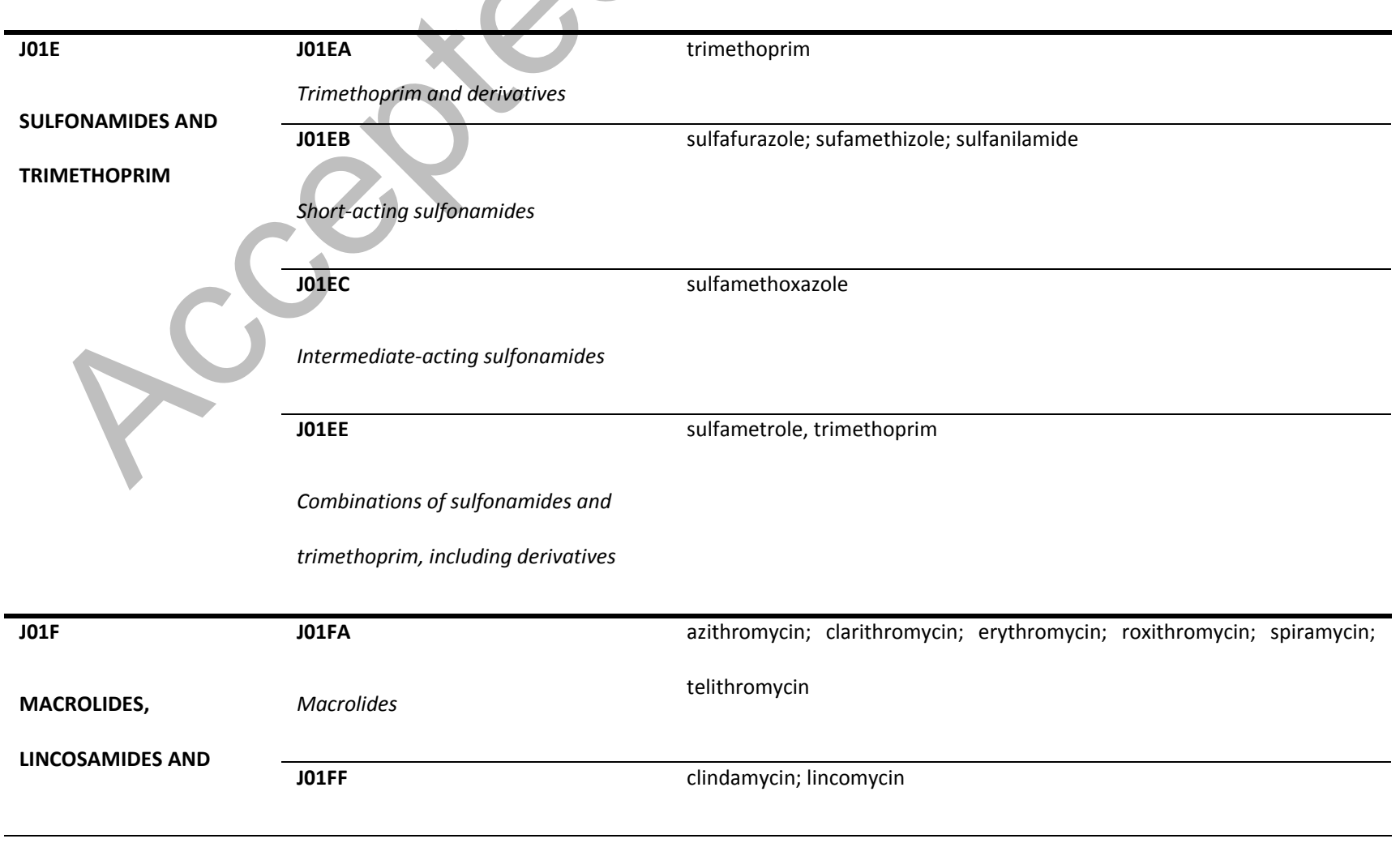




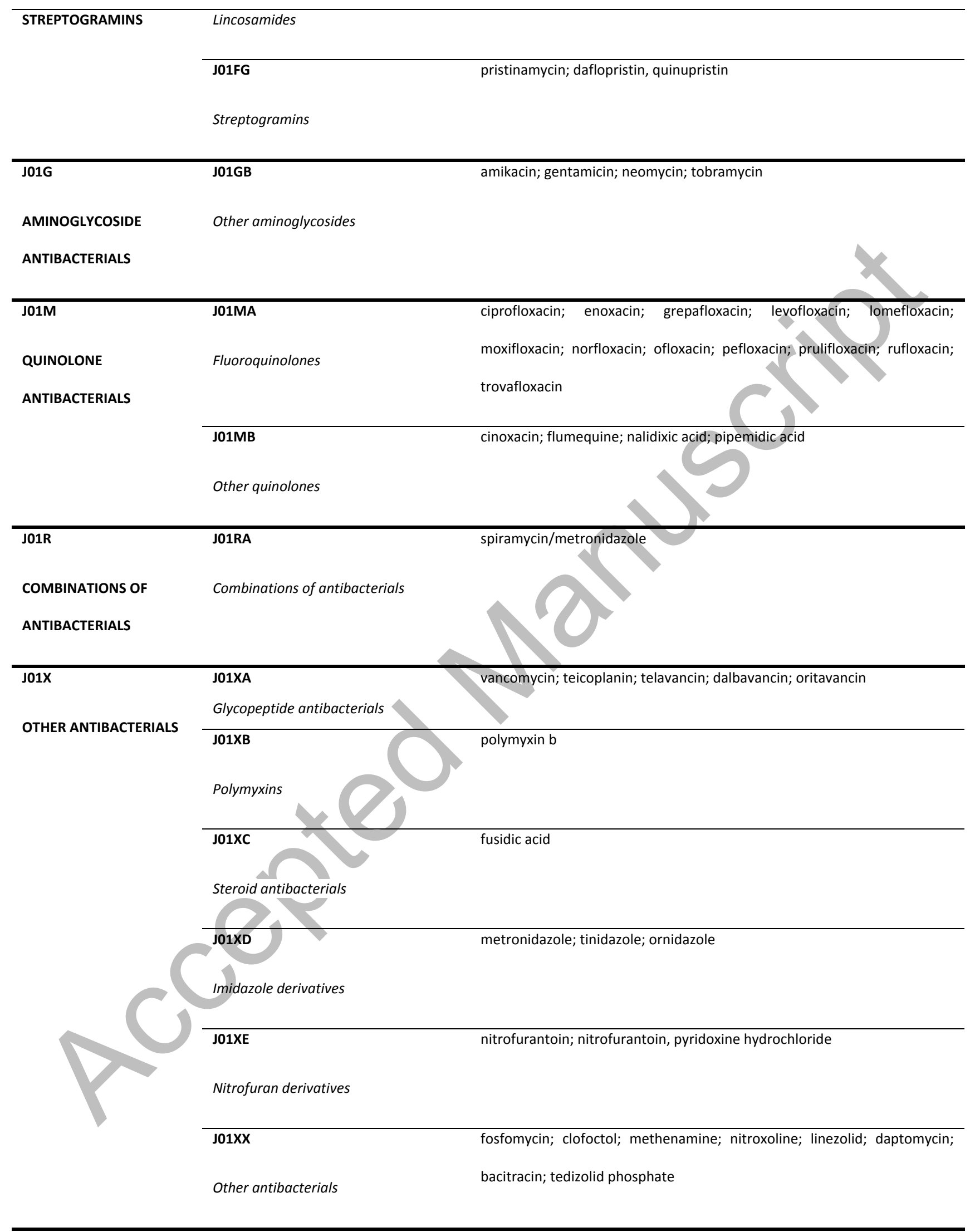

ATC: Anatomical Therapeutic Chemical 
Supplementary Table 3. Number of overall and GOA reactions associated with antibiotic classes according to third- and fourthlevels of ATC classification.

\begin{tabular}{|c|c|c|c|c|c|c|c|}
\hline ATC CLASS NAME & $\begin{array}{l}\text { Third-level } \\
\text { ATC class }\end{array}$ & $\begin{array}{l}\text { Fourth-level } \\
\text { ATC class }\end{array}$ & $\begin{array}{l}\text { Overall } \\
\text { reactions }\end{array}$ & $\begin{array}{l}\text { GOA } \\
\text { reactions }\end{array}$ & $\begin{array}{l}\text { Gustatory } \\
\text { reactions }\end{array}$ & $\begin{array}{l}\text { Olfactory } \\
\text { reactions }\end{array}$ & $\begin{array}{l}\text { Auditory } \\
\text { reactions }\end{array}$ \\
\hline TETRACYCLINES & J01A & J01AA & 28,905 & 458 & 158 & 62 & 238 \\
\hline AMPHENICOLS & J01B & J01BA & 1,368 & 25 & 21 & 0 & 4 \\
\hline \multirow{5}{*}{$\begin{array}{l}\beta \text {-LACTAMS and } \\
\text { PENICILLINS }\end{array}$} & J01C & J01CA & 56,626 & 470 & 243 & 58 & 168 \\
\hline & & J01CE & 12,663 & 93 & 33 & 2 & 59 \\
\hline & & J01CF & 9,651 & 50 & 24 & 2 & 24 \\
\hline & & J01CR & 89,273 & 382 & 165 & 41 & 176 \\
\hline & & & 168,213 & 995 & 465 & 103 & 427 \\
\hline \multirow{8}{*}{$\begin{array}{l}\text { OTHER } \beta \text {-LACTAMS } \\
\text { ANTIBACTERIALS }\end{array}$} & J01D & J01DB & 15,347 & 42 & 14 & 5 & 23 \\
\hline & & J01DC & 23,545 & 160 & 74 & 20 & 66 \\
\hline & & J01DD & 71,387 & 238 & 69 & 27 & 142 \\
\hline & & J01DE & 6,653 & 14 & 3 & 2 & 9 \\
\hline & & J01DI & 755 & 1 & 0 & 0 & 1 \\
\hline & & J01DF & 1,365 & 5 & 0 & 0 & 5 \\
\hline & & J01DH & 24,582 & & 26 & 6 & 121 \\
\hline & & & 143,634 & 613 & 186 & 60 & 367 \\
\hline \multirow{5}{*}{$\begin{array}{l}\text { SULFONAMIDES and } \\
\text { TRIMETHOPRIM }\end{array}$} & J01E & J01EA & 5,751 & 49 & 14 & 6 & 29 \\
\hline & & J01EB & 126 & 1 & 0 & 0 & 1 \\
\hline & & J01EC & 897 & 11 & 1 & 0 & 10 \\
\hline & & J01EE & 59 & 0 & 0 & 0 & 0 \\
\hline & & & 6,833 & 61 & 15 & 6 & 40 \\
\hline \multirow{4}{*}{$\begin{array}{l}\text { MACROLIDES, } \\
\text { LINCOSAMIDES } \\
\text { and } \\
\text { STREPTOGRAMINS }\end{array}$} & J01F & J01FA & 76,807 & 3,215 & 1,409 & 591 & 1,215 \\
\hline & & J01FF & 17,205 & 344 & 259 & 21 & 64 \\
\hline & & J01FG & 3,990 & 12 & 5 & 4 & 3 \\
\hline & & & 98,002 & 3,571 & 1,673 & 616 & 1,282 \\
\hline AMINOGLYCOSIDES & J01G & J01GB & 20,405 & 1,150 & 16 & 5 & 1,129 \\
\hline \multirow[t]{3}{*}{ QUINOLONES } & J01M & J01MA & 174,611 & 2,628 & 758 & 448 & 1,422 \\
\hline & & $\mathrm{J} 01 \mathrm{MB}$ & 421 & 1 & 0 & 0 & 1 \\
\hline & & & 175,032 & 2,629 & 758 & 448 & 1,423 \\
\hline $\begin{array}{l}\text { COMBINATIONS OF } \\
\text { ANTIBACTERIALS }\end{array}$ & J01R & J01RA & 928 & 11 & 5 & 0 & 6 \\
\hline \multirow{7}{*}{$\begin{array}{l}\text { OTHER } \\
\text { ANTIBACTERIALS }\end{array}$} & J01X & J01XA & 36,219 & 354 & 25 & 0 & 329 \\
\hline & & J01XB & 232 & 2 & 0 & 0 & 2 \\
\hline & & J01XC & 2,766 & 12 & 6 & 1 & 5 \\
\hline & & J01XD & 22,130 & 538 & 353 & 16 & 169 \\
\hline & & J01XE & 14,413 & 89 & 41 & 7 & 41 \\
\hline & & J01XX & 29,719 & 254 & 71 & 6 & 177 \\
\hline & & & 105,479 & 1,249 & 496 & 30 & 723 \\
\hline
\end{tabular}


Supplementary Table 4 a Number of overall and gustatory reactions reported for the listed antibiotic groups and organized by frequency of gustatory reactions according to their outcomes.

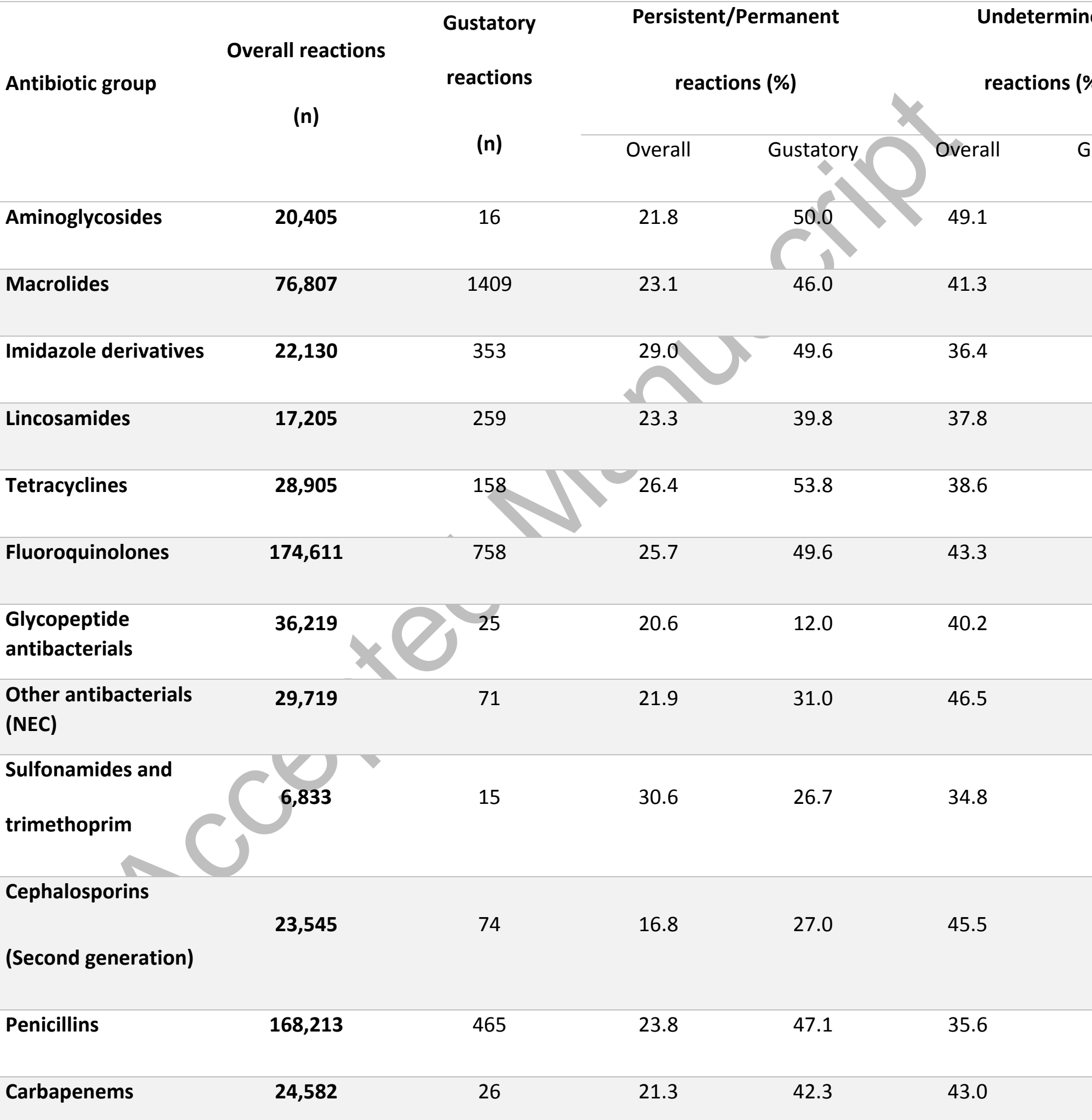



Nitrofuran
derivatives
14,413
41
33.9
53.9
29.6

\section{Cephalosporins}
71,387
69
29.5
42.0
31.5
(Third generation)
NEC: not elsewhere classified

Supplementary Table 4 b Number of overall and olfactory reactions reported for the listed antibiotic groups and organized by frequency of olfactory reactions according to their outcomes.

$\begin{array}{llccc} & & \text { Olfactory } & \text { Persistent/Permanent } & \text { Undetermine } \\ \text { Antibiotic group } & \text { Overall reactions } & \text { reactions } & \text { reactions }(\%) & \text { reactions }(\%\end{array}$

(n)

(n) Overall Olfactory Overall

\begin{tabular}{|c|c|c|c|c|c|}
\hline Aminoglycosides & 20,405 & 5 & 21.8 & 57.1 & 49.1 \\
\hline Macrolides & 76,807 & 591 & 23.1 & 60.9 & 41.3 \\
\hline Imidazole derivatives & 22,130 & 16 & 29.0 & 62.5 & 36.4 \\
\hline Lincosamides & 17,205 & 21 & 23.3 & 57.1 & 37.8 \\
\hline Tetracyclines & 28,905 & 62 & 26.4 & 80.6 & 38.6 \\
\hline Fluoroquinolones & 174,611 & 448 & 25.7 & 60.9 & 43.3 \\
\hline $\begin{array}{l}\text { Glycopeptide } \\
\text { antibacterials }\end{array}$ & 36,219 & - & 20.6 & - & 40.2 \\
\hline $\begin{array}{l}\text { Other antibacterials } \\
\text { (NEC) }\end{array}$ & 29,719 & 6 & 21.9 & 66.7 & 46.5 \\
\hline Sulfonamides and & & & & & \\
\hline trimethoprim & 6,833 & 6 & 30.6 & 66.7 & 34.8 \\
\hline Cephalosporins & 23,545 & 20 & 16.8 & 80.0 & 45.5 \\
\hline
\end{tabular}


(Second generation)

Penicillins

Carbapenems

\section{Nitrofuran}

derivatives

\section{Cephalosporins}

(Third generation)

71,387

27

29.5

66.7

31.5

103

6

7

33.9

71.4

29.6

NEC: not elsewhere classified

Supplementary Table $4 \mathrm{c}$ Number of overall and auditory reactions reported for the listed antibiotic groups and organized by frequency of auditory reactions according to their outcomes.

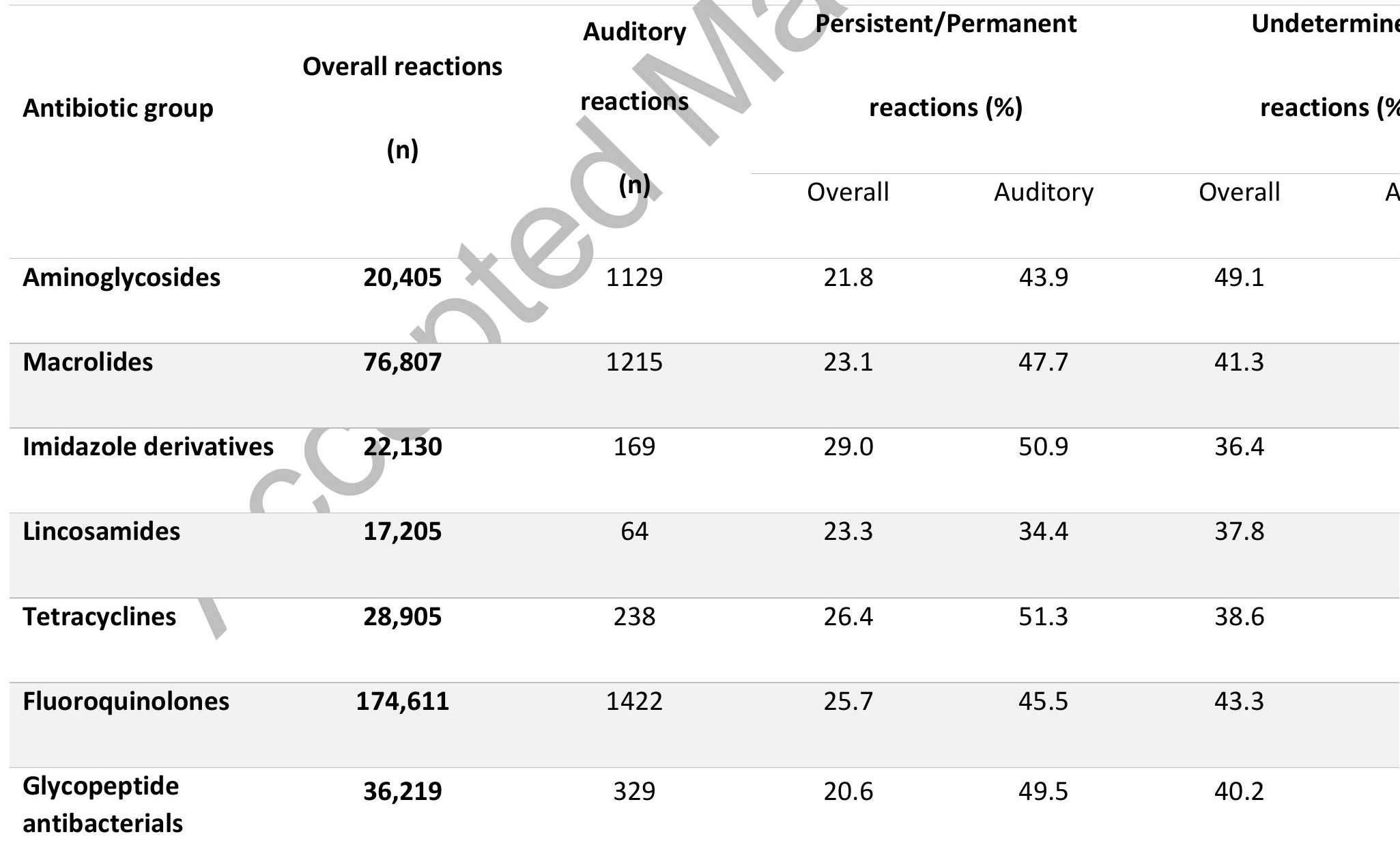




\begin{tabular}{llcccc}
\hline $\begin{array}{l}\text { Other antibacterials } \\
\text { (NEC) }\end{array}$ & $\mathbf{2 9 , 7 1 9}$ & 177 & 21.9 & 41.8 & 46.5 \\
\hline $\begin{array}{l}\text { Sulfonamides and } \\
\text { trimethoprim }\end{array}$ & $\mathbf{6 , 8 3 3}$ & 40 & 30.6 & 50.0 & 34.8 \\
\hline
\end{tabular}

\section{Cephalosporins \\ (Second generation) \\ Penicillins \\ Carbapenems \\ Nitrofuran \\ derivatives \\ Cephalosporins}

$\begin{array}{llll}23,545 & 66 & 16.8 & 33.3\end{array}$

(Third generation)

427

121

24,582

14,413

41

33.9

23.8

41.2

21.3

34.7

53.7

29.6

NEC: not elsewhere classified

\section{1,38}

29.5

52.1

31.5

35.6

43.0

45.5 


\begin{tabular}{|ccccc|}
\hline tigecycline & 8 & 9 & 1 & 18 \\
\hline all drugs & 257 & 138 & 63 & 45 \\
\hline
\end{tabular}
each drug.

Supplementary Table 5 p Cephalosporines (third generation) and GOA reactions: outcomes and proportions (\% value) of

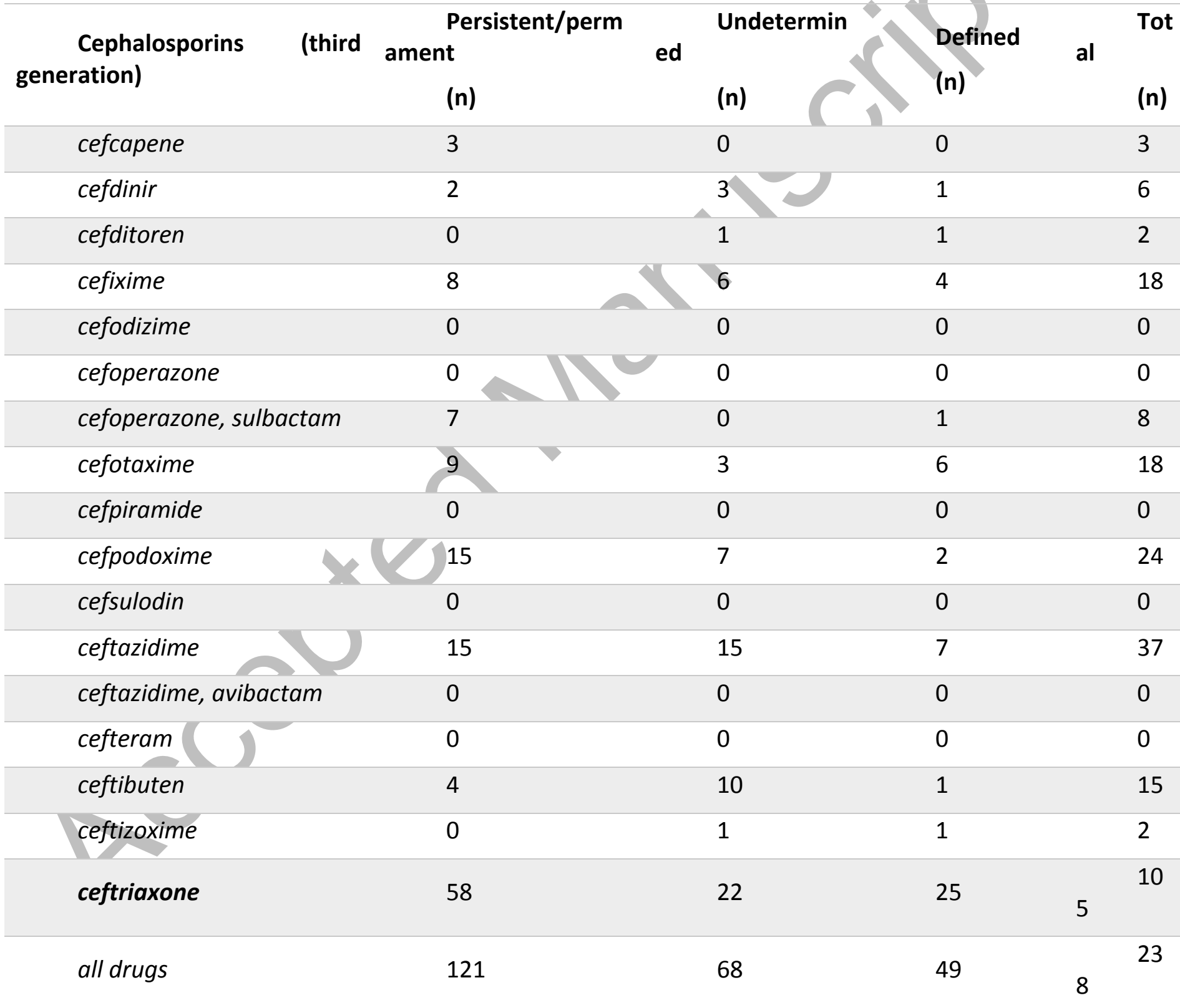

Supplementary Table 5 q Nitrofuran derivatives and GOA reactions: outcomes and proportions (\% value) of each drug. 


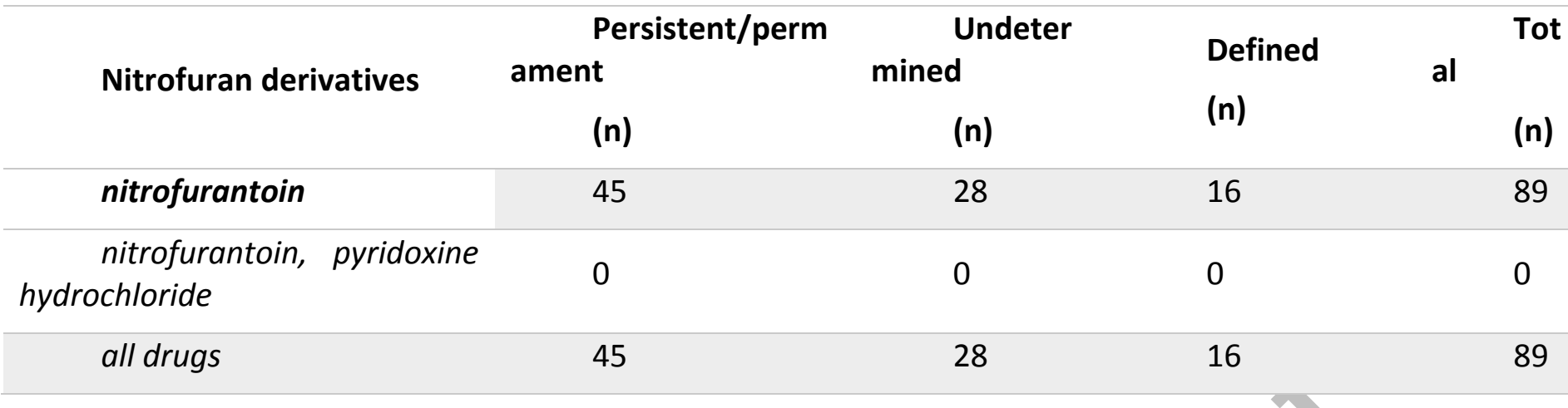

Supplementary Table $5 \mathbf{r}$ Imidazole derivatives and GOA reactions: outcomes and proportions (\% value) of each drug.

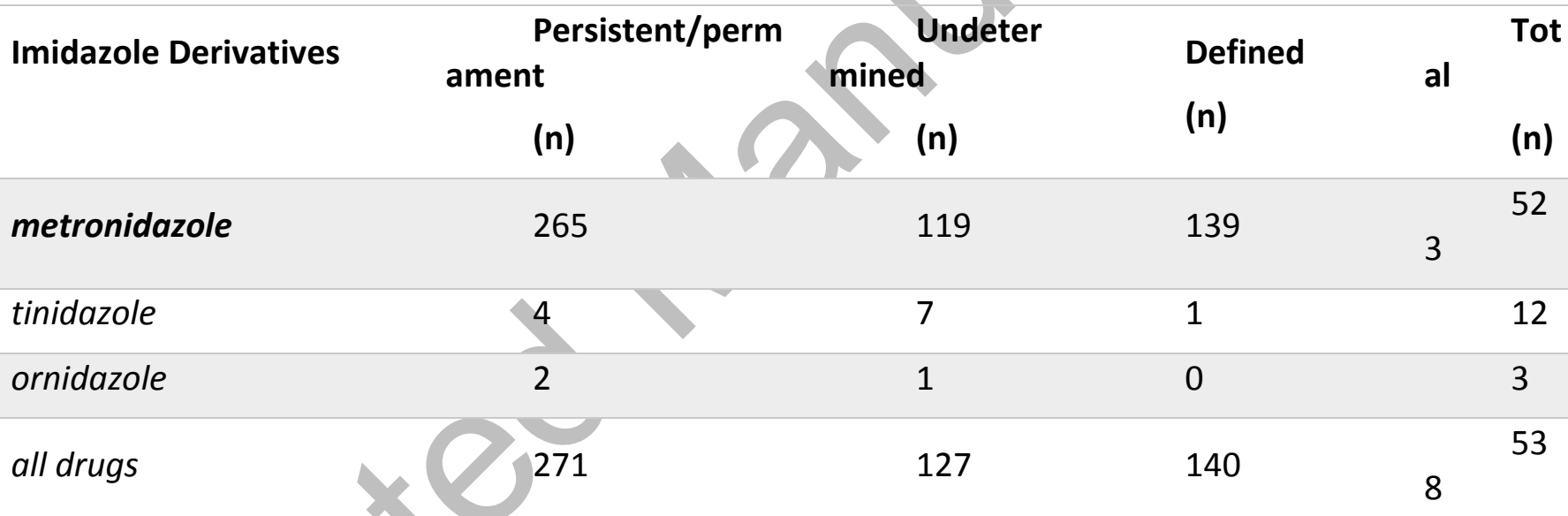

Supplementary Table 5 s Fluoroquinolones and GOA reactions: outcomes and proportions (\% value) of each drug.

\begin{tabular}{|c|c|c|c|c|}
\hline Fluoroquinolones & $\begin{array}{l}\text { Persistent/perm } \\
\text { ament } \\
\text { (n) }\end{array}$ & $\begin{array}{l}\text { Undeter } \\
\text { mined } \\
\text { (n) }\end{array}$ & $\begin{array}{l}\text { Defined } \\
\text { (n) }\end{array}$ & al \\
\hline ofloxacin & 88 & 102 & 32 & 2 \\
\hline ciprofloxacin & 413 & 321 & 146 & 0 \\
\hline pefloxacin & 0 & 0 & 0 & \\
\hline enoxacin & 1 & 2 & 2 & \\
\hline
\end{tabular}




\begin{tabular}{|lllll|}
\hline norfloxacin & 18 & 13 & 9 & 40 \\
\hline lomefloxacin & 6 & 1 & 1 & 8 \\
\hline rufloxacin & 0 & 1 & 0 & 1 \\
\hline grepafloxacin & 6 & 4 & 4 & 14 \\
\hline levofloxacin & 387 & 217 & 115 & 71 \\
\hline trovafloxacin & 10 & 1 & 144 & 12 \\
\hline moxifloxacin & 363 & 213 & 0 & 72 \\
\hline prulifloxacin & 4 & 3 & 0 & 7 \\
\hline all drugs & 1296 & 878 & 454 & 28 \\
\hline
\end{tabular}

Supplementary Table 5 t Macrolides and GOA reactions: outcomes and proportions (\% value) of each drug.

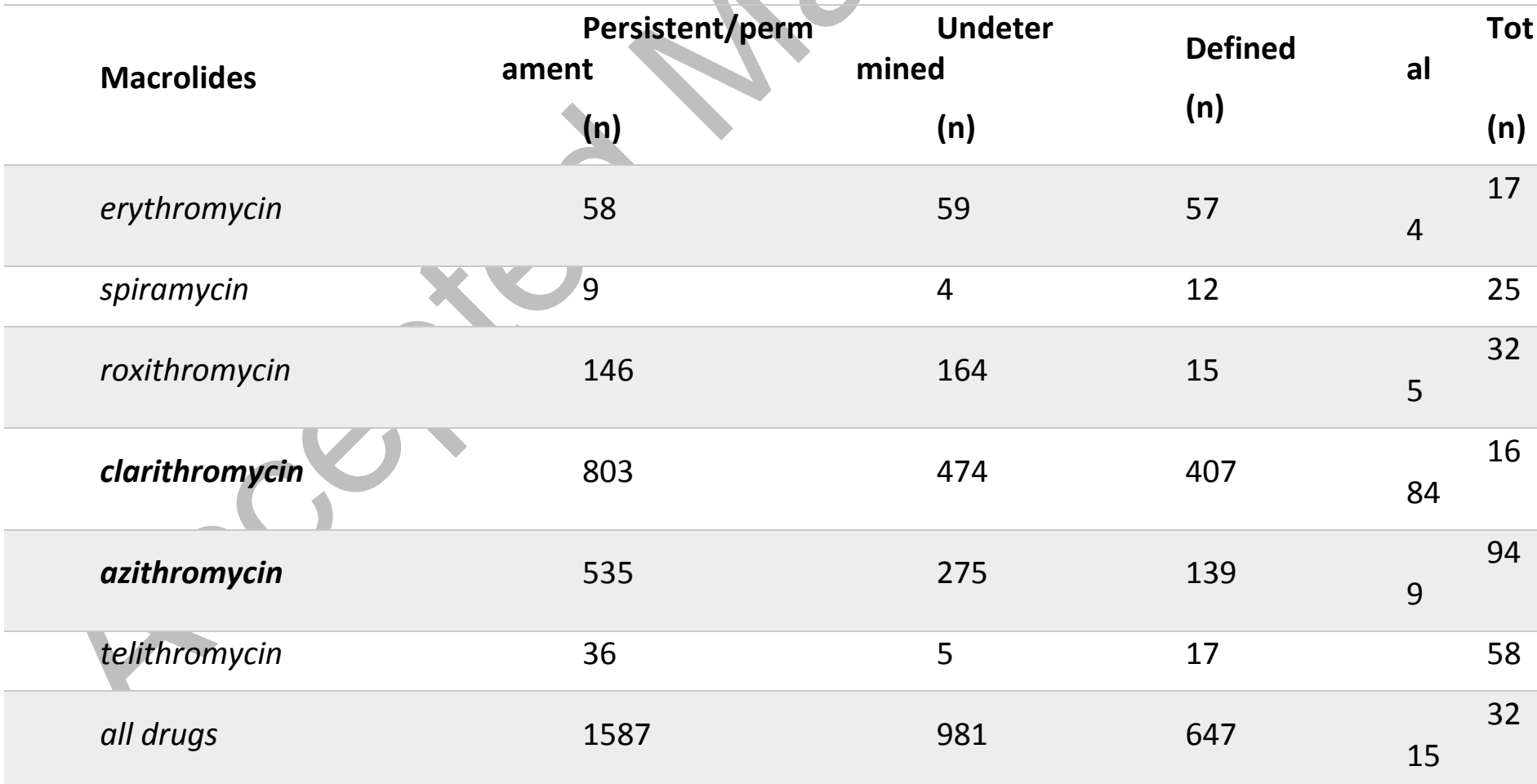




\begin{tabular}{|c|c|c|c|c|}
\hline $\begin{array}{l}\text { Glycopeptide } \\
\text { antibacterials }\end{array}$ & $\begin{array}{l}\text { Persistent/perm } \\
\text { ament } \\
\text { (n) }\end{array}$ & $\begin{array}{l}\text { Undeter } \\
\text { mined } \\
\text { (n) }\end{array}$ & $\begin{array}{l}\text { Defined } \\
\text { (n) }\end{array}$ & al \\
\hline vancomycin & 149 & 111 & 50 & 0 \\
\hline teicoplanin & 17 & 15 & 7 & \\
\hline telavancin & 0 & 3 & 2 & \\
\hline dalbavancin & 0 & 0 & 0 & \\
\hline oritavancin & 0 & 0 & 0 & \\
\hline all drugs & 166 & 129 & & \\
\hline
\end{tabular}

Supplementary Table 5 v Sulfonamides and trimethoprim and GOA reactions: outcomes and proportions (\% value) of each drug.

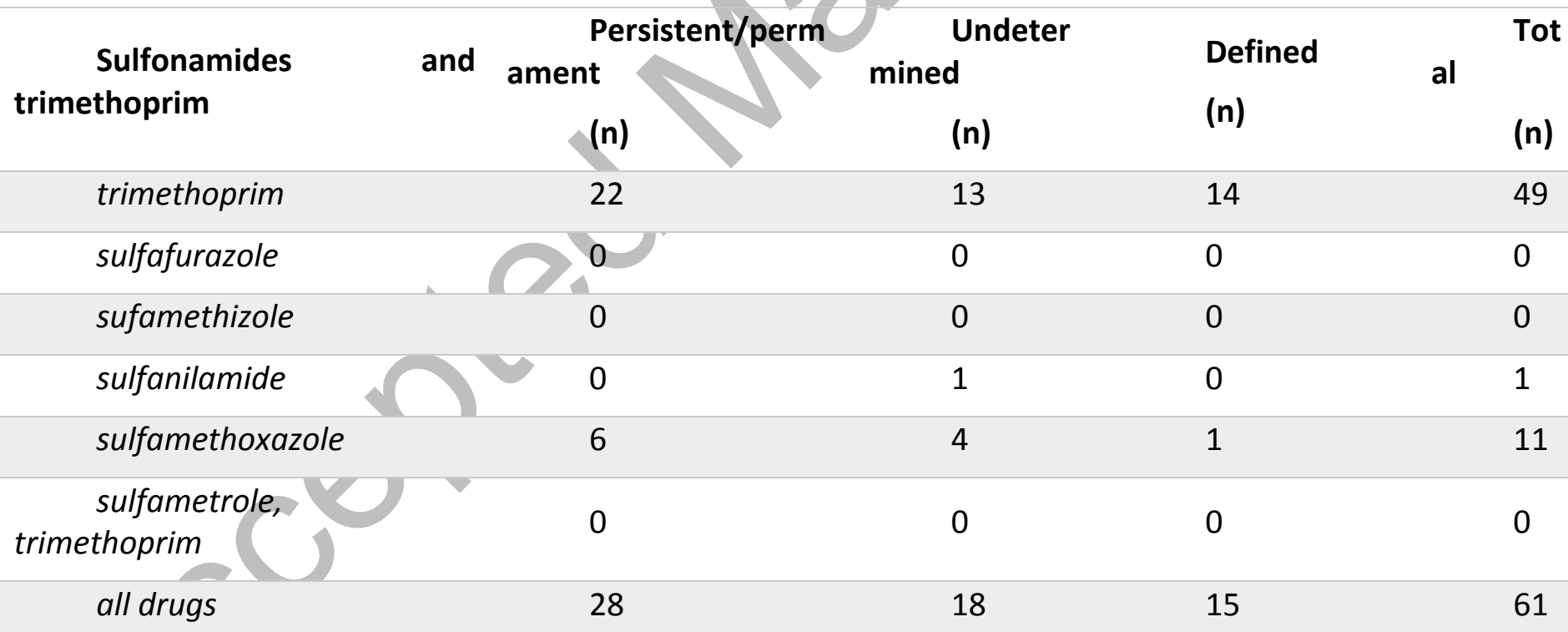

Supplementary Table 5 w Penicillins and GOA reactions: outcomes and proportions (\% value) of each drug.

Penicillins

$\begin{array}{lll}\text { Persistent/perm } & \text { Undeter } & \text { Defined } \\ \text { ament } & \text { mined } & \text { (n) }\end{array}$

(n) 


\begin{tabular}{|c|c|c|c|c|c|}
\hline & (n) & (n) & & & (n) \\
\hline ampicillin & 3 & 8 & 2 & & 13 \\
\hline pivampicillin & 0 & 0 & 0 & & 0 \\
\hline carbenicillin & 1 & 0 & 0 & & 1 \\
\hline amoxicillin & 230 & 108 & 91 & 9 & 42 \\
\hline bacampicillin & 1 & 0 & 0 & & 1 \\
\hline pivmecillinam & 7 & 0 & 2 & & 9 \\
\hline mezlocillin & 0 & 1 & 0 & & 1 \\
\hline piperacillin & 6 & 3 & 5 & & 14 \\
\hline ticarcillin & 0 & 2 & 0 & & 2 \\
\hline temocillin & 0 & 0 & 0 & & 0 \\
\hline benzathine benzylpenicillin & 1 & 2 & 1 & & 4 \\
\hline $\begin{array}{l}\text { benzathine } \\
\text { benzylpenicillin, lidocaine } \\
\text { hydrochloride }\end{array}$ & 0 & 0 & 0 & & 0 \\
\hline $\begin{array}{l}\quad \text { benzathine } \\
\text { benzylpenicillin, procaine } \\
\text { benzylpenicillin monohydrate }\end{array}$ & 0 & 1 & 0 & & 1 \\
\hline $\begin{array}{c}\text { benzathine } \\
\text { phenoxymethylpenicillin }\end{array}$ & & 0 & 1 & & 1 \\
\hline benzylpenicillin & 4 & 4 & 7 & & 15 \\
\hline penamecillin & 0 & 0 & 0 & & 0 \\
\hline phenoxymethylpenicillin & 25 & 15 & 13 & & 53 \\
\hline procaine benzylpenicillin & 4 & 7 & 8 & & 19 \\
\hline cloxacillin & 4 & 3 & 1 & & 8 \\
\hline dicloxacillin & 4 & 0 & 0 & & 4 \\
\hline flucloxacillin & 27 & 5 & 6 & & 38 \\
\hline oxacillin & 0 & 0 & 0 & & 0 \\
\hline ampicillin, sulbactam & 7 & 3 & 7 & & 17 \\
\hline $\begin{array}{l}\text { amoxicillin, clavulanic } \\
\text { acid }\end{array}$ & 114 & 108 & 65 & 7 & 28 \\
\hline sultamicillin & 3 & 8 & 4 & & 15 \\
\hline piperacillin, tazobactam & 14 & 24 & 23 & & 61 \\
\hline ampicillin trihydrate, & 2 & 0 & 0 & & 2 \\
\hline
\end{tabular}




\begin{tabular}{|c|c|c|c|c|}
\hline ampicillin, cloxacillin & 0 & 0 & 0 & 0 \\
\hline all drugs & 457 & 302 & 236 & 99 \\
\hline
\end{tabular}

Supplementary Table 5 x Aminoglycosides and GOA reactions: outcomes and proportions (\% value) of each drug.

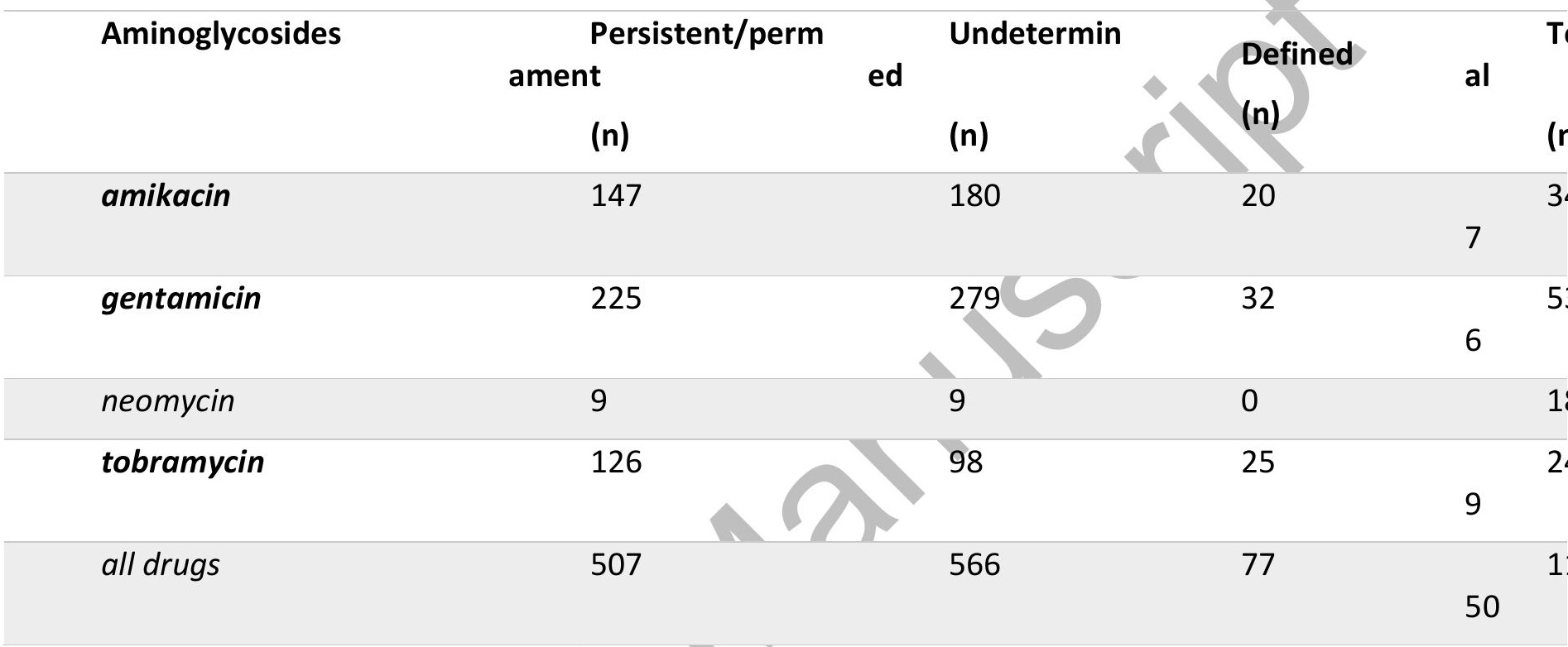

Supplementary Table 5 y Lincosamides and GOA reactions: outcomes and proportions (\% value) of each drug.

\begin{tabular}{|c|c|c|c|c|}
\hline Lincosamides & $\begin{array}{l}\text { Persistent/perm } \\
\text { ament } \\
\text { (n) }\end{array}$ & $\begin{array}{l}\text { Undeter } \\
\text { mined } \\
\text { (n) }\end{array}$ & $\begin{array}{l}\text { Defined } \\
\text { (n) }\end{array}$ & al \\
\hline clindamycin & 137 & 103 & 102 & 2 \\
\hline lincomycin & 0 & 2 & 0 & \\
\hline all drugs & 137 & 105 & 102 & 4 \\
\hline
\end{tabular}


Supplementary Table $5 \mathrm{z}$ Carbapenems and GOA reactions: outcomes and proportions (\% value) of each drug.

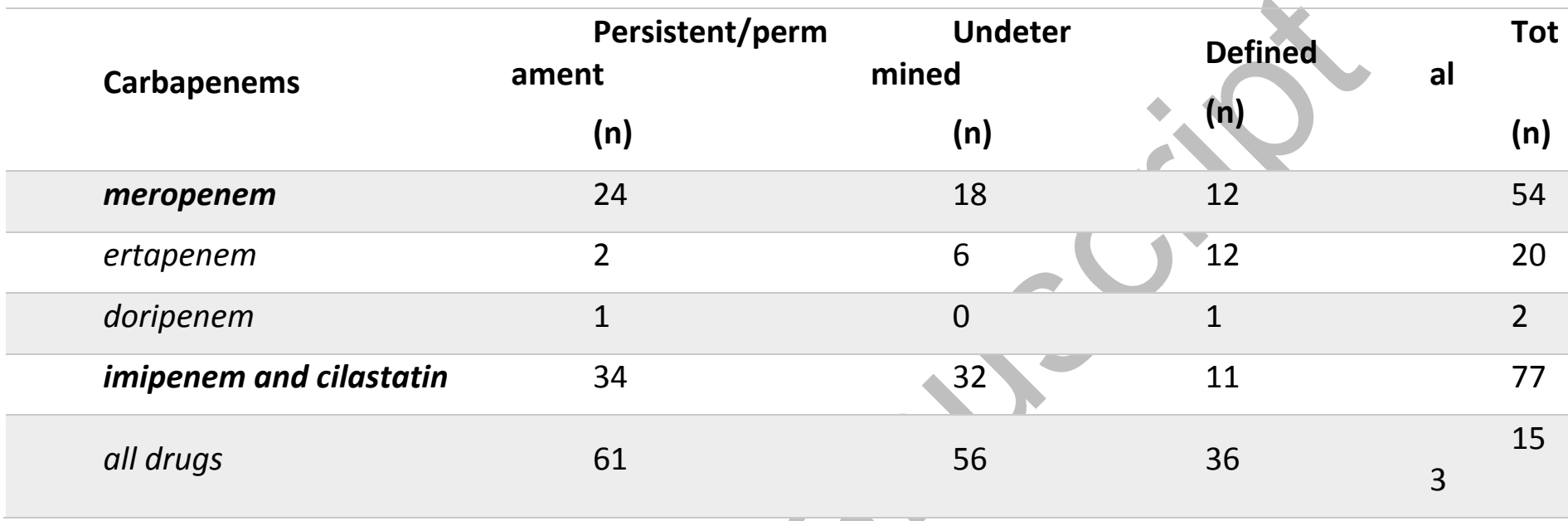

Supplementary Table 5 aa Other antibacterials and GOA reactions: outcomes and proportions (\% value) of each drug.

\begin{tabular}{|c|c|c|c|c|}
\hline $\begin{array}{l}\text { Other } \\
(\mathrm{NEC})^{*}\end{array}$ & $\begin{array}{l}\text { Persistent/perm } \\
\text { ament } \\
\text { (n) }\end{array}$ & $\begin{array}{l}\text { Undeter } \\
\text { mined } \\
\text { (n) }\end{array}$ & $\begin{array}{l}\text { Defined } \\
\text { (n) }\end{array}$ & $\begin{array}{l}\text { Tot } \\
\text { (n) }\end{array}$ \\
\hline fosfomycin & 19 & 6 & 10 & 35 \\
\hline clofoctol & 0 & 0 & 0 & 0 \\
\hline methenamine & 0 & 2 & 0 & 2 \\
\hline
\end{tabular}




\begin{tabular}{|ccccc|}
\hline nitroxoline & 1 & 0 & 0 & 1 \\
\hline linezolid & 64 & 66 & 54 & 4 \\
\hline daptomycin & 14 & 12 & 3 & 29 \\
\hline bacitracin & 2 & 1 & 0 & 3 \\
\hline all drugs & 100 & 87 & 67 & 4 \\
\hline
\end{tabular}

Supplementary Table 5 bb Cephalosporins (Second generation) and GOA reactions: outcomes and proportions (\% value) of each drug.

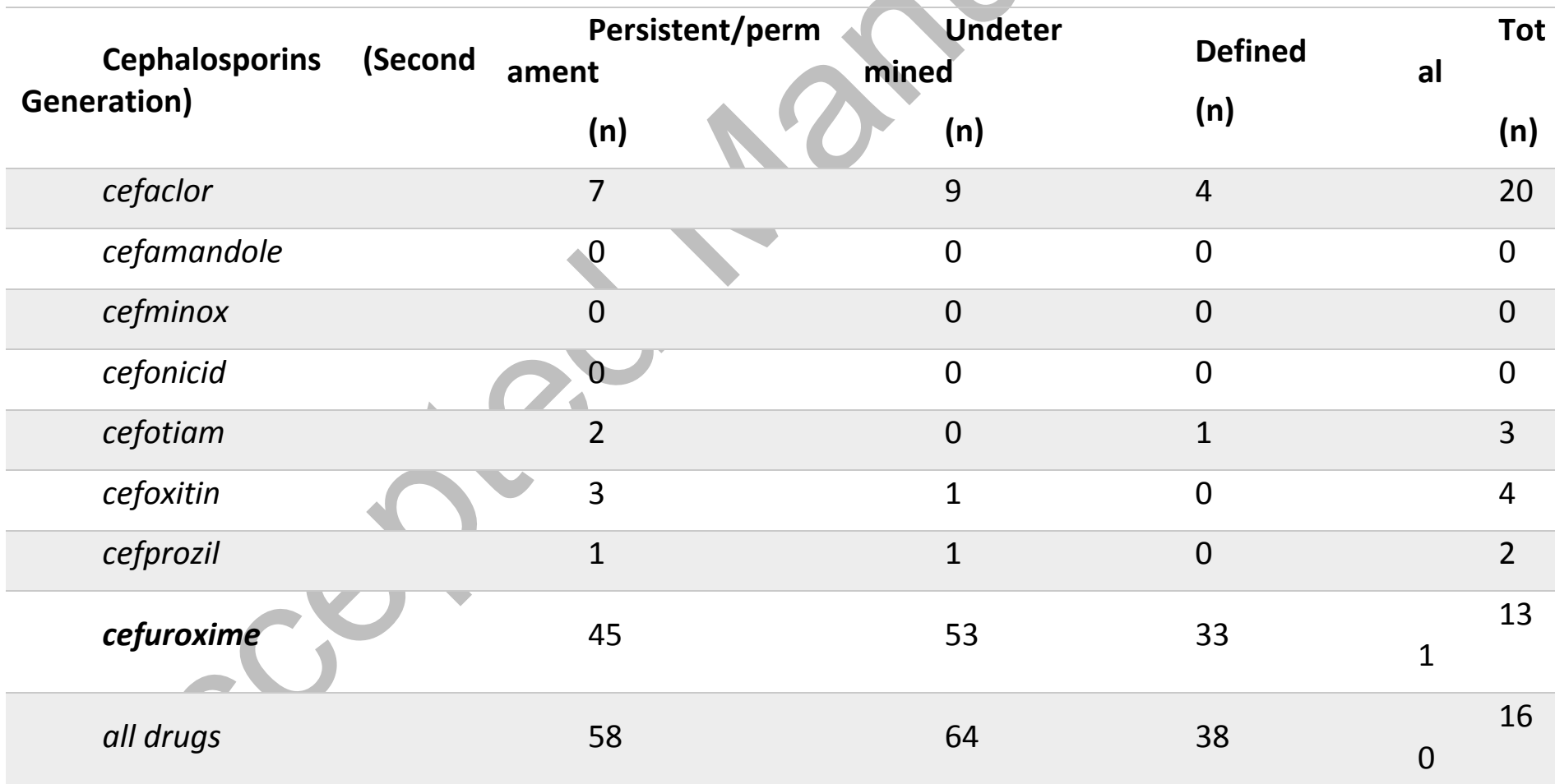




\section{Figure 1.}
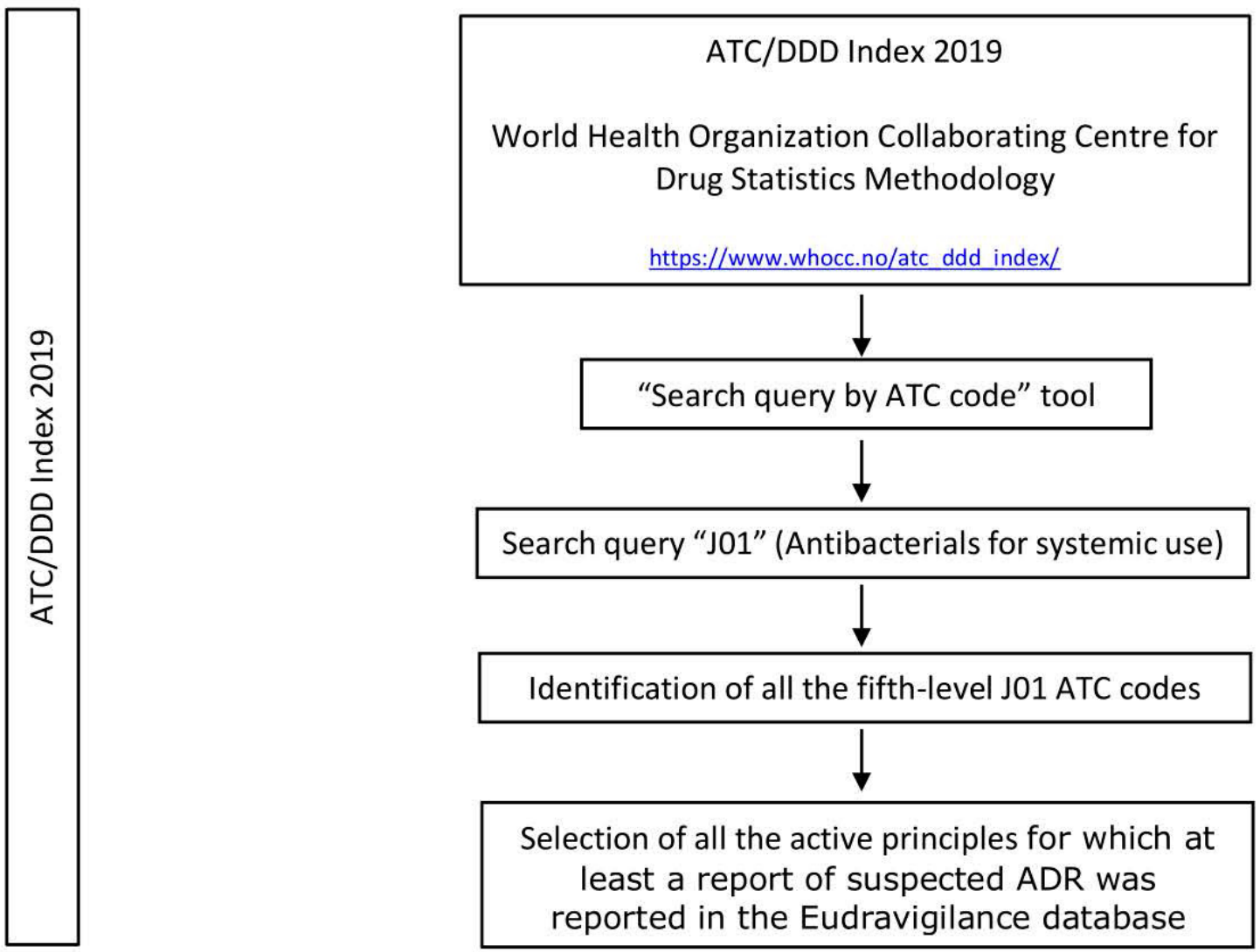

EudraVigilance - European database of suspected adverse drug reaction reports

Online access to suspected side-effect reports

http://www.adrreports.eu/en/index.html

"Search here for suspected adverse drug reactions reports" tool

Acceptance of disclaimer

Suspected adverse drug reaction reports were searched by "substances" (browsed by alphabetic order) 


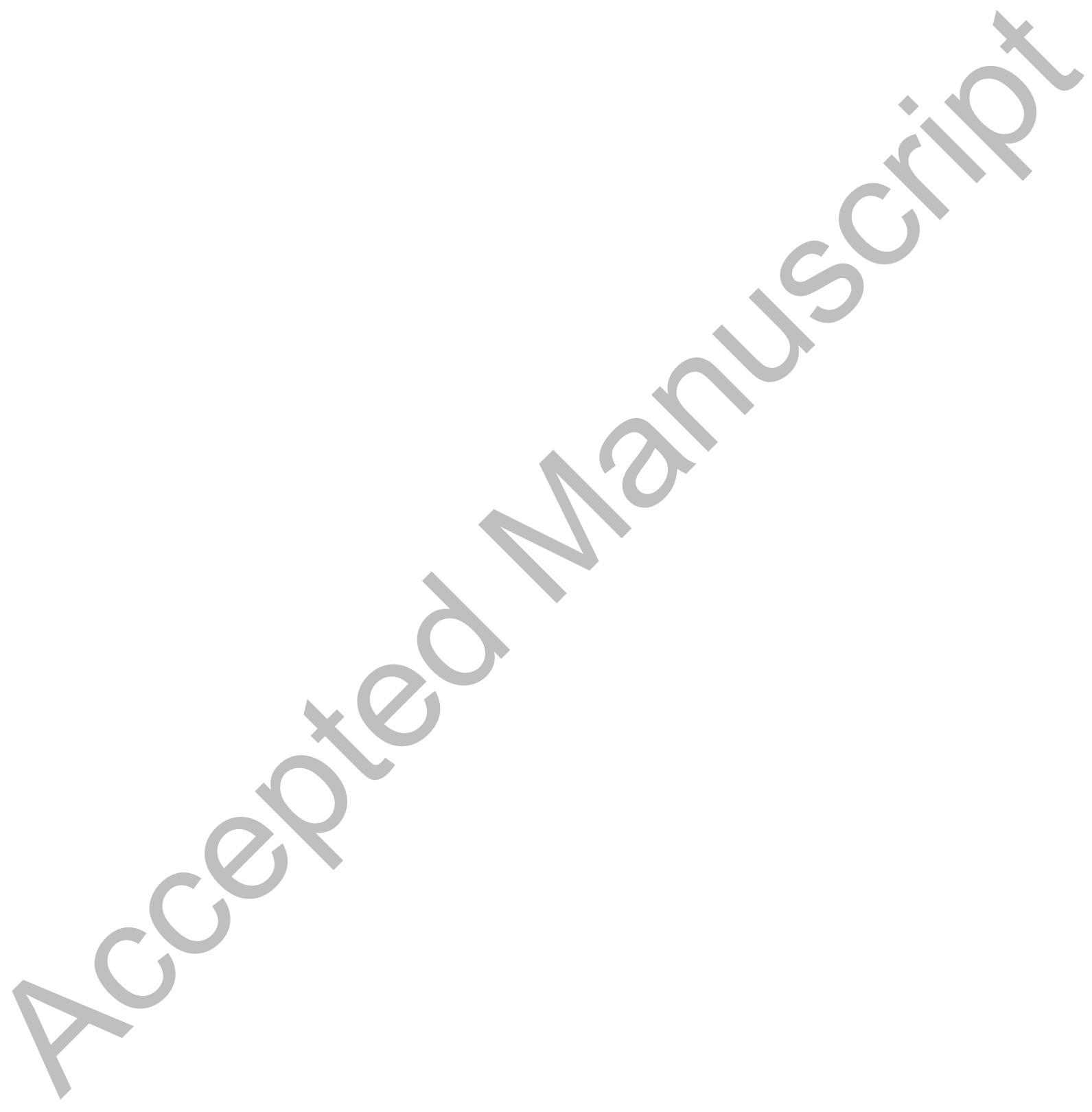

